UNIVERSIDADE DE SAO PAULO

FACULDADE DE CIENCIAS FARMACEUTICAS

Curso de Pós-Graduação em Fármaco e Medicamentos

Area de Produção e Controle Farmacêuticos

\title{
COMPRIMIDOS DE IBUPROFENO: FORMULAÇÃO E AVALIAÇAOO DO PERFIL DE DISSOLUÇÃO
}

HUMBERTO GOMES FERRAZ

Dissertação para obtenção do grau de MESTRE

Orientador:

Prof. Dr. REYNALDO NACCO

São Paulo 


\section{HUMBERTO GOMBS FERRAZ}

COYPRIMIDOS DR IBUPROEBNO: FOREULACEO

B AVALIAGEO DO PERTIL DB DISSOLOCXO

\section{DISSRRTACAO PARA OBTENCEO DO GRAO DR MESTRE}

COUISSAO JULGADORA

Trof. Ax. Peynaldo Ybuceo.

$\frac{\text { Profa Nea Silura Stoppixtis. }}{\text { 10 BXaminador }}$

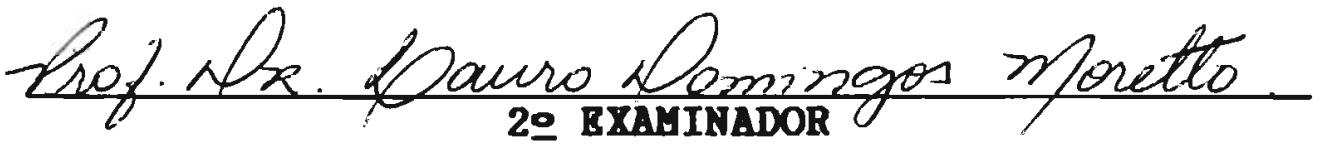

SAO PAULO, O马 DE junho. DE 1993. 
AOS MEOS PAIS,

PELO AMOR, PELA COMPREENSAO,

PELAS OPORTUNIDADES, PELA VIDA...

A HELENA,

POR TUDO... 
A conclusão de um curso de pós-graduação é uma tarefa àrdua, e, neste sentido, o auxilio prestado pelos amigos é imprescindivel. De um modo ou de outro, muitas pessoas contribuiram neste trabalho. Gostaria de fazer citação especial:

Ao Prof. Dr. Reinaldo Nacco, pela orientação e amizade.

As professoras do setor de farmacotécnica Silvia Storpirtis, Vladi O. Consiglieri e Maria Valéria R. Velasco, cujo apoio foi fundamental para a viabilização deste trabalho.

A professora Ida Caramico Soares e à farmacêutica Maria Aparecida Nicolette do PROFAR, não apenas pela permissão do uso de alguns equipamentos aqui utilizados, mas também pela atenção e simpatia demonstradas.

Ao Prof. Dr. Lauro D. Moretto, pelas valiosas sugestões apresentadas.

As amigas Hyun, Yoshie, Ana Luiza e Nádia, aos amigos João Paulo e José de Jesus pela amizade e simpatia com que sempre me distinguiram.

Aos companheiros de CRUSP Geraldo e Graça pelo convivio durante quase todo o curso de pós-graduação. 
As secretárias da seção de pós-graduação Benedita e Luiza e à secretária do curso de pós-graduação em Fàrmaco e Medicamentos, Beth, pela simpatia e atenção, a mim sempre dispensadas.

As funcionàrias do setor de farmacotécnica, Fátima e d. Regina, pela amizade e constante apoio.

Aos funcionários da biblioteca do conjunto das quimicas, em especial às bibliotecárias Marina, pela elaboração da ficha catalográfica, e Moema, pelo trabalho de revisão das referências bibliográficas e pela grande simpatia e atenção sempre demonstradas.

A d. Tokue, sr. Sebastião, ao Carlos e Eliza, ao Eduardo e Cristina, pelo carinho e atenção com que me receberam.

A todos os meus parentes, que sempre acreditaram em mim, especialmente à José Otávio e Rosana, pelo apoio imprescindivel na minha adaptação à São Paulo.

A Universidade de São Paulo, pelas oportunidades.

à todos, o meu mais sincero 


\section{- INDICR -}

CAPITULO I:

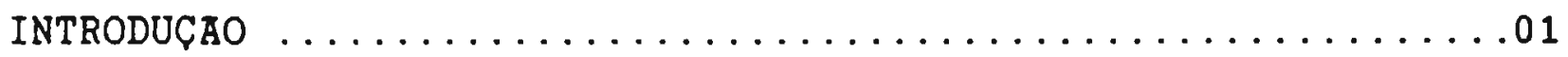

CAPITULO II:

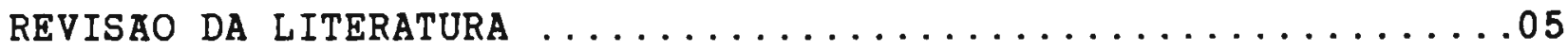

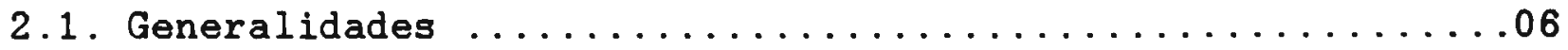

2.2. Aspectos farmacológicos e mecanismo de ação $\ldots \ldots \ldots \ldots . . \ldots 7$

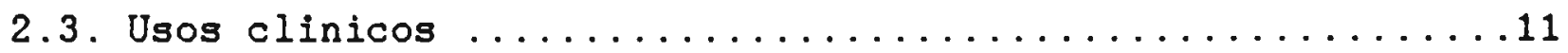

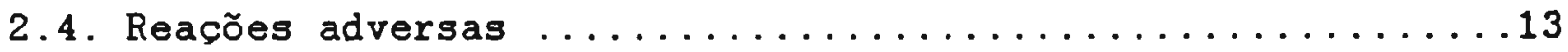

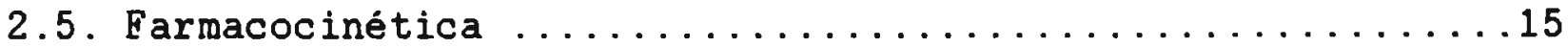

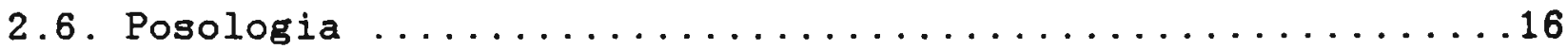

2.7. Ibuprofeno e prescrição médica $\ldots \ldots \ldots \ldots \ldots \ldots \ldots \ldots \ldots$

2.8. Formas farmacêuticas do ibuprofeno $\ldots \ldots \ldots \ldots \ldots \ldots \ldots \ldots$

2.9. Dissoluçăo de comprimidos de ibuprofeno $\ldots \ldots \ldots \ldots \ldots \ldots 18$

2.10. Fatores determinantes da dissolução de formas farmacêti-

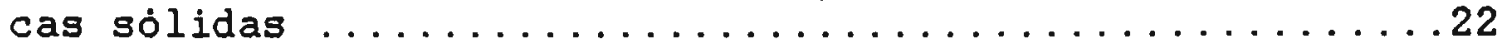

2.10.1. Propriedades fisico-quimicas do fármaco $\ldots \ldots \ldots \ldots 24$

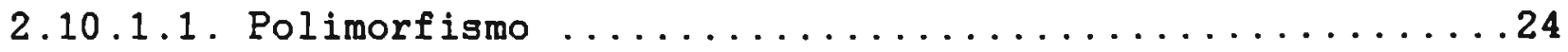

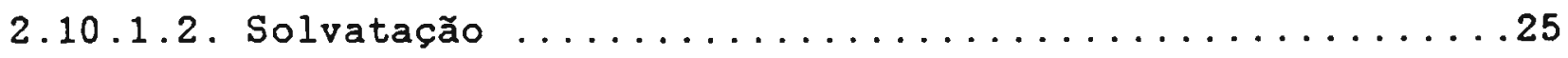

2.10.1.3. Base livre, ácido livre ou forma salina ........26

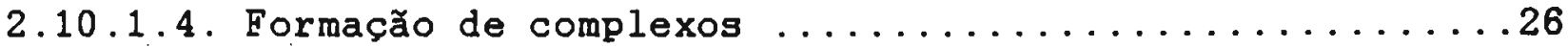

2.10.2. Fatores tecnologicos ......................

2.10.2.1. Influência dos componentes da formulação ........27

2.10.2.1.1. Influência dos diluentes $\ldots \ldots \ldots \ldots \ldots \ldots \ldots \ldots \ldots \ldots$

2.10 .2 .1 .2 . Influência dos desagregantes $\ldots \ldots \ldots \ldots \ldots \ldots \ldots$ 
2.10.2.1.3. Influência dos aglutinantes $\ldots \ldots \ldots \ldots \ldots \ldots \ldots \ldots 29$

2.10.2.1.4. Influência dos lubrificantes ...............30

2.10.2.1.5. Influência de tensioativos .................

2.10.2.2. Influência do método de granulação empregado na produ

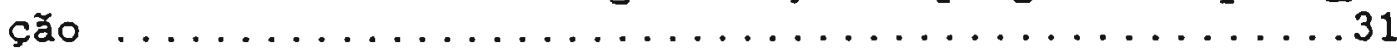

2.10.2.3. Influência da granulometria .................. 32

2.10.2.4. Influência da força de compressão .............33

2.10 .3 . Idade da forma farmacêutica $\ldots \ldots \ldots \ldots \ldots \ldots \ldots \ldots \ldots$

CAPITULO III:

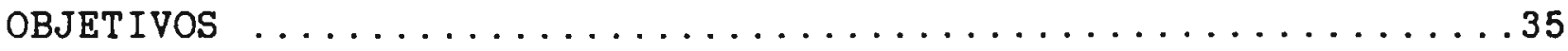

CAPITULO IV:

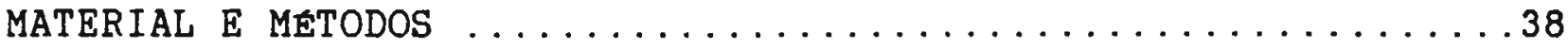

4.1. Preparo dos comprimidos ......................

4.1.1. Planejamento estatistico das formulações . . . . . . . . . 39

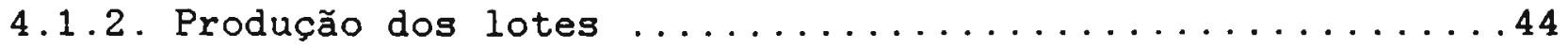

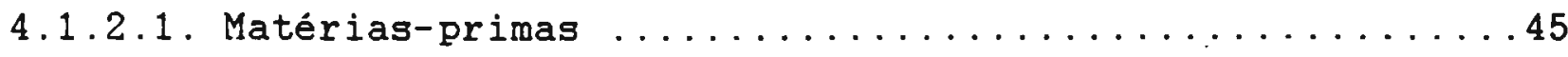

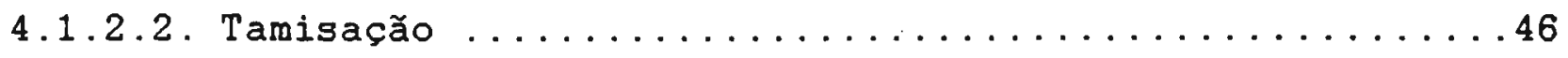

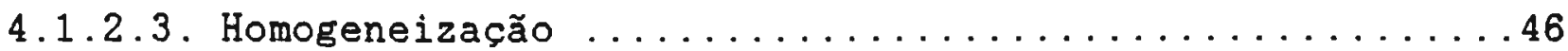

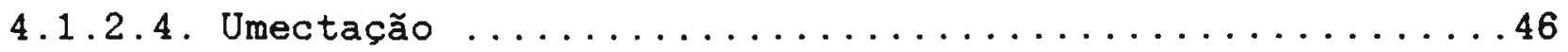

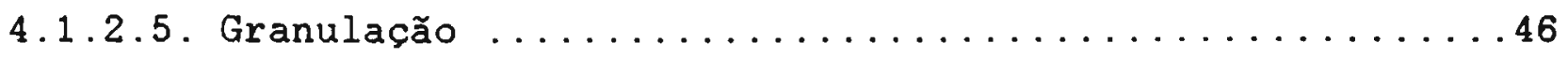

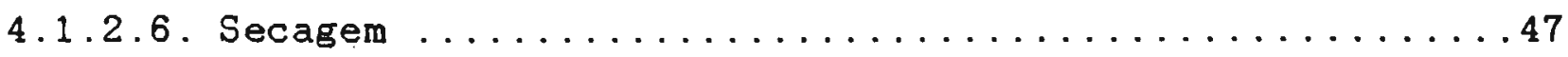

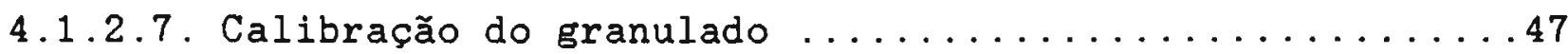

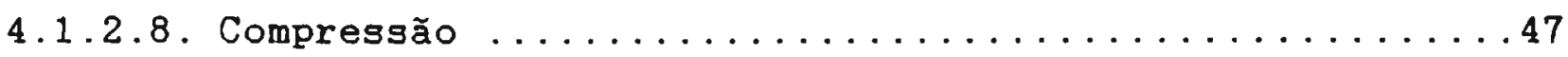

4.2. Anàlises fisico-quimicas $\ldots \ldots \ldots \ldots \ldots \ldots \ldots \ldots \ldots \ldots$

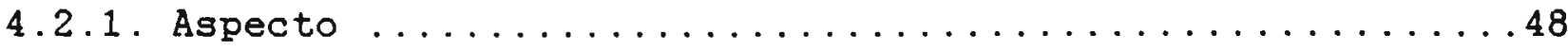




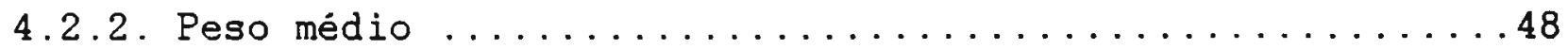

4.2.3. Dureza, diâmetro e espessura ...............48

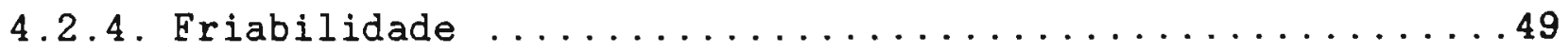

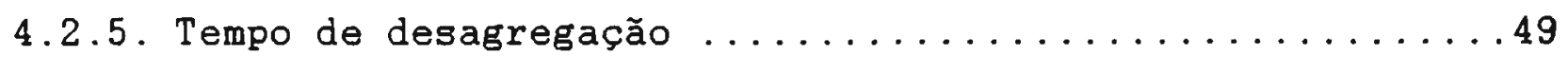

4.2.6. Dissolução ....................... 49

4.2.7. Teor de ibuprofeno ..........................

4.3. Análise e interpretação dos resultados obtidos .......55

4.3.1. Anàlise exploratória ..................... 53

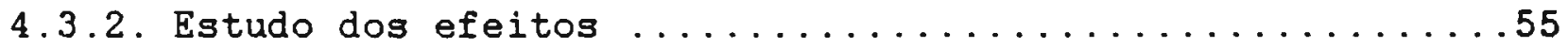

4.4. Estabilidade fisica das formulações $\ldots \ldots \ldots \ldots \ldots \ldots \ldots$

CAPITULO V:

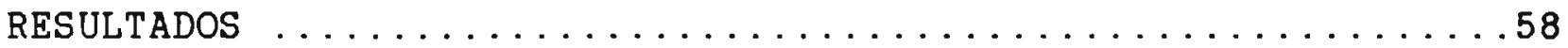

PARTE I: ANALISES FISICO-QUIMICAS E INTERPRETACAO $\ldots \ldots \ldots \ldots 59$

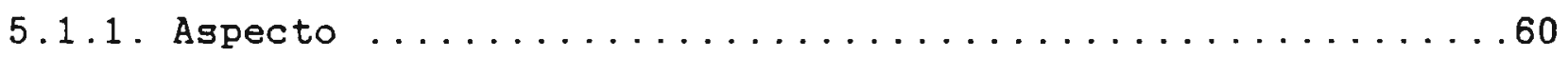

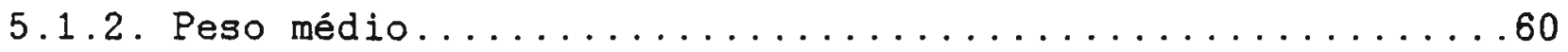

5.1.3. Dureza, friabilidade, diâmetro e espessura dos comprimi-

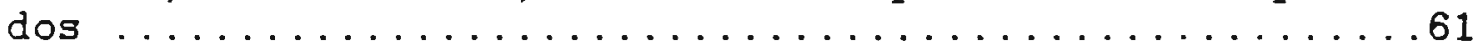

5.1.4. Ensaios de desagregação, dissolução e teor dos comprimi-

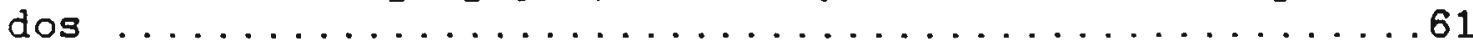

5.1.5. Relação entre as variàveis respostas $\ldots \ldots \ldots \ldots \ldots 66$

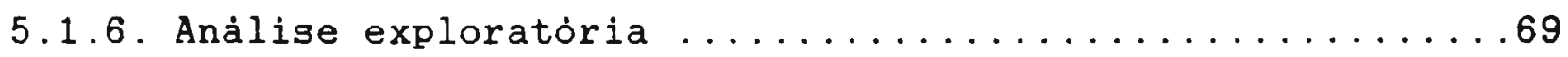

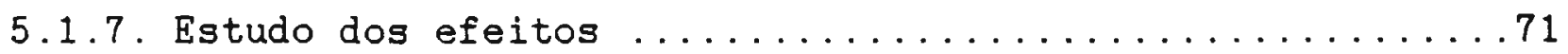

PARTE II: ESTABILIDADE FISICA DAS FORMULAÇõES $\ldots \ldots \ldots \ldots \ldots 72$

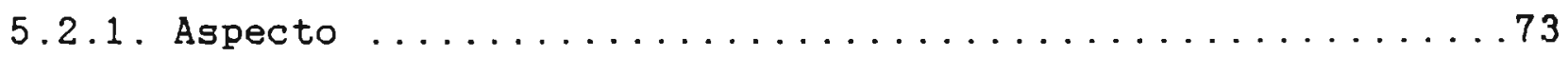

5.2.1.1. Comprimidos submetidos à temperatura ambiente ......73

5.2.1.2. Comprimidos submetidos à temperatura de 37 oC (estufa)73

5.2.1.3. Comprimidos submetidos à temperatura de 50 oC (estufa)73 
5.2.2. Peso médio, espessura, diâmetro, friabilidade, dureza e desagregação dos comprimidos .................. . . 44

CAPITULO VI:

DISCUSSAO

.86

CAPITULO VII:

CONCLUSÕES .96

REEERENCIAS BIBL IOGRAF ICAS

.99

RESUMO 112

ABSTRACT .114 
CAPITULO I : INTRODUCAO

Neste capitulo, que serve de preâmbulo ao presente trabalho. são apresentadas a linha de pensamento e a justificativa deste, através de uma abordagem suscinta do tema biodisponibilidade de formas farmacêticas sólidas. 
Dentre as diversas vias de administração de medicamentos, a via oral é, sem dúvida, a mais importante e a mais utilizada. Se considerarmos as diversas formas farmacêuticas hoje existentes e disponiveis à terapêtica para serem administradas por esta via, as formas farmacêuticas sólidas, em especial os comprimidos, ocupam posição de destaque.

De fato, a produção das formas farmacêuticas sòlidas é destaque na maioria das industrias farmacêticas, e, quando do descobrimento de um novo fármaco, este é, sempre que possivel lançado no mercado sob esta apresentação (BANKER \& ANDERSON, 1986).

As principais vantagens habitualmente atribuidas aos comprimidos em relação à outras formas farmacêuticas, são (BANKER \& ANDERSON, 1986; WAGNER, 1969):

- Os comprimidos são uma forma unitària de dosagem que oferece a maior capacidade, dentre todas as outras formas farmacêuticas, de precisão de dose e menor variabilidade no conteúdo;

- Apresentam o mais baixo custo dentre as formas farmacêticas;

- Apresentam forma compacta, favorecendo embalagem e transporte;

- Apresentam boa estabilidade quimica, mecânica e microbiológica. 
Por outro lado, se considerarmos o ponto de vista biofarmacêutico, os comprimidos são medicamentos que podem apresentar sérios problemas. A figura 1 apresenta o esquema de liberação, seguido de absorção, do principio ativo contido num comprimido (CARCAMO, 1981; CESCHEL et alii, 1973; FLORENCE \& HALBERT , 1990 ; GIBALDI, 1991).

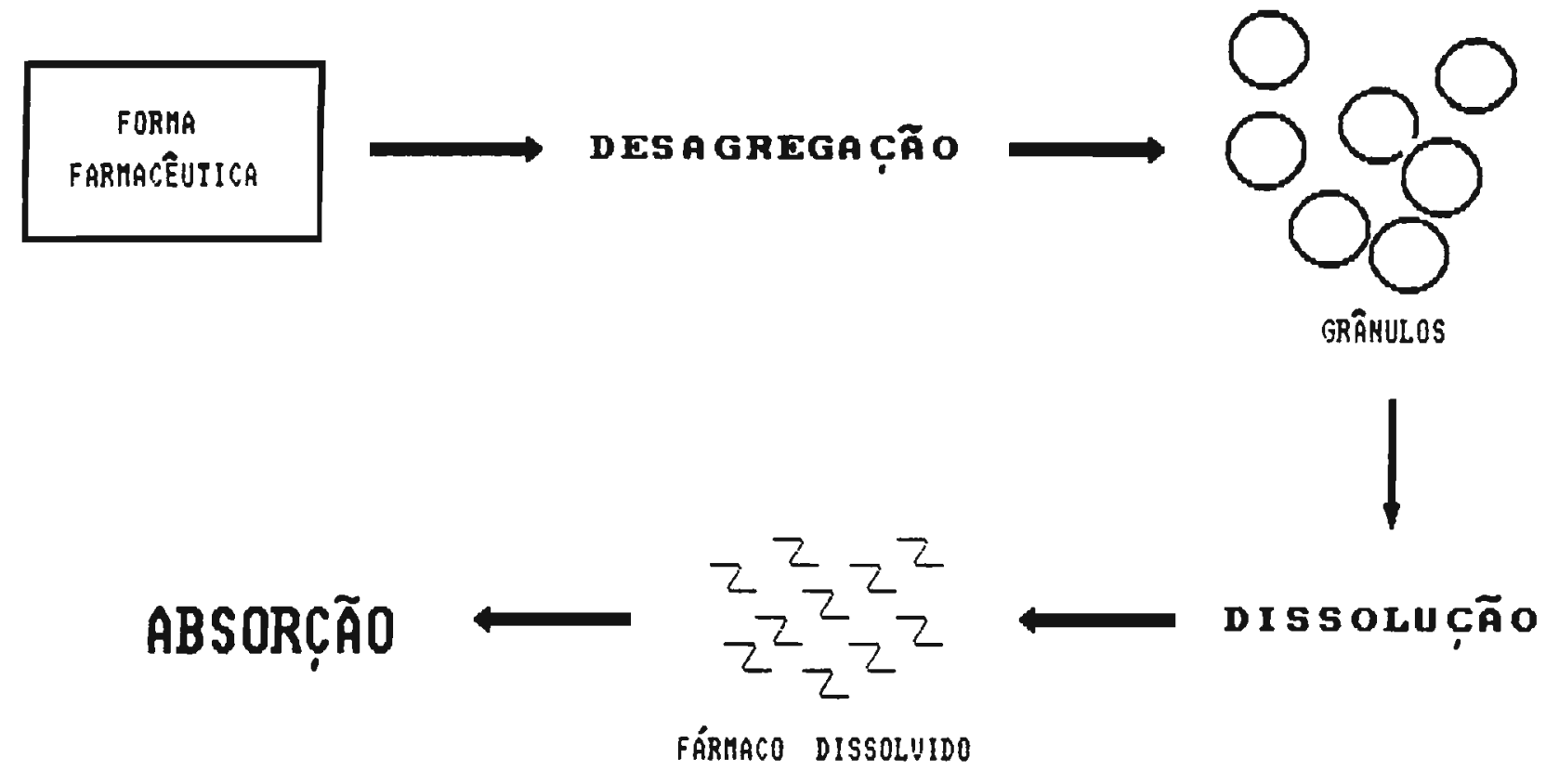

Figura 1 : Esquema representativo da liberação do principio ativo contido num comprimido.

Nota-se, então, que os passos a serem seguidos até a liberação do princlpio ativo contido na forma farmacêutica podem retardar sobremaneira a liberação deste $e$, consequientemente, a absorção. Esta, aliás, deve ser a principal preocupação do formulador, quando da elaboração desta forma farmacêtica. 
Embora novos sistemas carreadores de fármacos (BARRY, 1987; FREISE \& MAGERSTEDT, 1986; LUZZI \& PALMIERI, 1984) estejam sendo desenvolvidos, e com o avanço das pesquisas poderà haver modificações no quadro atual, o destaque das formas farmacêuticas sólidas é ainda muito grande. Considerando-se todos estes aspectos, pode-se afirmar que as formas farmacêuticas sólidas são um campo imenso para pesquisas em biofarmàcia e farmacotécnica.

Considerando-se ainda, que o ibuprofeno, um antiinflamatório não-esteroidal introduzido na Inglaterra em 1969 (SITTIG, 1988), è hoje um fármaco bastante utilizado na terapêutica em casos de artrite reumatóide, dores e dismenorréia primària (FLOWER et alii, 1987) e que este não é comercializado no Brasil na concentração de $200 \mathrm{mg}$ (DEF, 1990), este estudo tentará, observando-se o que foi acima analisado, apresentar uma formulação de comprimidos de ibuprofeno nesta concentração. 


\section{CAPITULO II =}

\section{REVISAO DA LITERATURA}

Na presente revisão, foram abordados aspectos farmacológicos relativos ao ibuprofeno. Além disto, o tema dissolução também foi tratado, especificamente para o farmaco e em relaça às formas farmacêuticas sólidas de uma maneira geral. 
2.1. GENERALIDADES:

0 ibuprofeno, quimicamente denominado ácido 2-(4isobutilfenil)-propiônico, àcido $\alpha$-metil-4-(2-metilpropil) benzenoacético ou ácido p-isobutilhidratrópico ( MERCK INDEX, 1989), é um sòlido cristalino, incolor, relativamente insolùvel em àgua e solúvel nos solventes orgânicos, e em soluções aquosas de hidróxidos alcalinos e carbonatos (MARTINDALE, 1989). O färmaco encontra-se descrito em várias farmacopéias: britânica (BRITISH PHARMACOPOEIA, 1988), internacional (INTERNATIONAL PHARMACOPOEIA, 1981), americana (USP XXII, 1990), japonesa (PHARMACOPOEIA OF JAPAN, 1986). A fórmula estrutural do ibuprofeno é a seguinte:

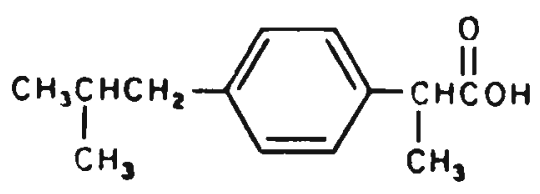

Trata-se de um anti-inflamatòrio não esteroidal (AINE), com propriedades analgésicas e antitérmicas, sendo empregado na terapêutica nas concentrações de $200,300,400$ e $600 \mathrm{mg}$. E indicado em casos de dores discretas e moderadas, artrite reumatóide, osteoartrite e na dismenorréia primária (DRUGDEX, 1992; DRUG EVALUATIONS, 1991; MARTINDALE, 1989). 
A primeira publicação sobre o fármaco data de 1967 (ADAMS et alii, 1967). Até aquele ano, os pesquisadores da empresa inglesa Boots Pure Drug Co. LTD, estavam estudando vàrios derivados do àcido propiônico, em especial o ibufenac - àcido acético(4-isobutilfenil) - (ADAMS et alii, 1963). Nesta primeira publicação, os autores relatavam que o ibuprofeno era, até então, - derivado que apresentava maior atividade farmacológica, sendo de 4 a 8 vezes mais ativo que o ibufenac. A partir deste ponto, inúmeros trabalhos sobre o composto foram publicados e, em 1969 o fármaco era lançado no mercado farmacêutico inglês, e, em 1974 nos EUA (SITTIG, 1988).

2.2. ASPECTOS FARMACOLOGICOS E MECANISMO DE ACAO:

As drogas antiinflamatórias, analgésicas e antipiréticas constituem um grupo heterogêneo de compostos, em geral não relacionados quimicamente (embora a maioria seja àcidos orgânicos) que, apesar disso, têm em comum certas propriedades terapêuticas e efeitos colaterais. A aspirina é o protótipo deste grupo, sendo por esta razão, denominados drogas tipo aspirina. Também são conhecidos como antiinflamatórios não-esteroidais (AINE) (ELOWER, 1974; FLOWER et alii, 1987).

Com relação ao mecanismo de ação desta drogas, houve um progresso acentuado na sua elucidação, sendo agora possivel entender porque drogas tão heterogêneas possuem as mesmas atividades terapêuticas básicas e, freqüentemente, os mesmos 
efeitos colaterais. A atividade terapêtica parece depender bastante da inibição de uma via bioquimica definida, responsàvel pela biossintese das prostaglandinas e de outras substâncias relacionadas (autacóides), produzidas pelas células (FLOWER, 1974; FLOWER et alii, 1987; GRYGLEWSKI, 1979; VANE, 1971).

Embora saiba-se que essa classe de drogas inibe diversas reações in vitro, não se pode estabelecer uma relação convincente com seus conhecidos efeitos antiinflamatorios, antipiréticos e analgésicos. Sabe-se que baixas concentrações destas drogas inibem a produção enzimática de prostaglandinas, e que estas participam da patogênese da inflamação e da febre, reforçando a hipótese de que a inibição da biosintese desses autacóides podia explicar um número considerável de ações clinicas destas drogas (VANE, 1971; VANE \& BOTTING, 1987).

Alguns fatos reforçam esta hipotese, tais como (ELOWER, et alii 1987):

(1) todos os tipos de células de mamiferos (exceto os eritrócitos), possuem enzimas microssômicas para a sintese das prostaglandinas; 
(2) as prostaglandinas são sempre liberadas quando ocorrem danos às células e foram detectadas em altas concentrações em exsudatos inflamatórios. Todas as evidências disponiveis indicam que as células não armazenam prostaglandinas e sua liberação depende, portanto, de nova sintese;

(3) todas os AINEs inibem a biossintese e a liberação de prostaglandinas em todas as células testadas;

(4) com exceção dos glicocorticóides antiinflamatórios, outras classes de drogas, em geral, não afetam a biossintese das prostaglandinas.

A inibição da biossintese das prostaglandinas pelos AINEs foi demonstrada em vários sistemas in vivo e in vitro (FLOWER, 1974), sendo este efeito irrestrito a qualquer espécie ou tecido, dependendo apenas da droga alcançar uma enzima especifica: a cicloxigenase. Os AINEs, então, inibem a conversão do àcido araquidônico no intermediàrio endoperóxido instável, PGG2, o qual é catalisado pela cicloxigenase (figura 2). Portanto, a distribuição e as propriedades farmacocinéticas das drogas têm relação importante com a sua atividade.

Doses terapêticas dos AINEs reduzem a biossintese de prostaglandinas no homem, reduzindo a sua produção pelas plaquetas humanas e a sua concentração no sêmen humano e de seus metabólitos na urina, alêm de reduzir, também, a sua concentração 
no liquido sinovial em joelhos com artrite. Existe uma correlaçăo razoavelmente boa entre a atividade antienzimática dessas drogas e sua atividade antiinflamatória (SHEN, 1979).

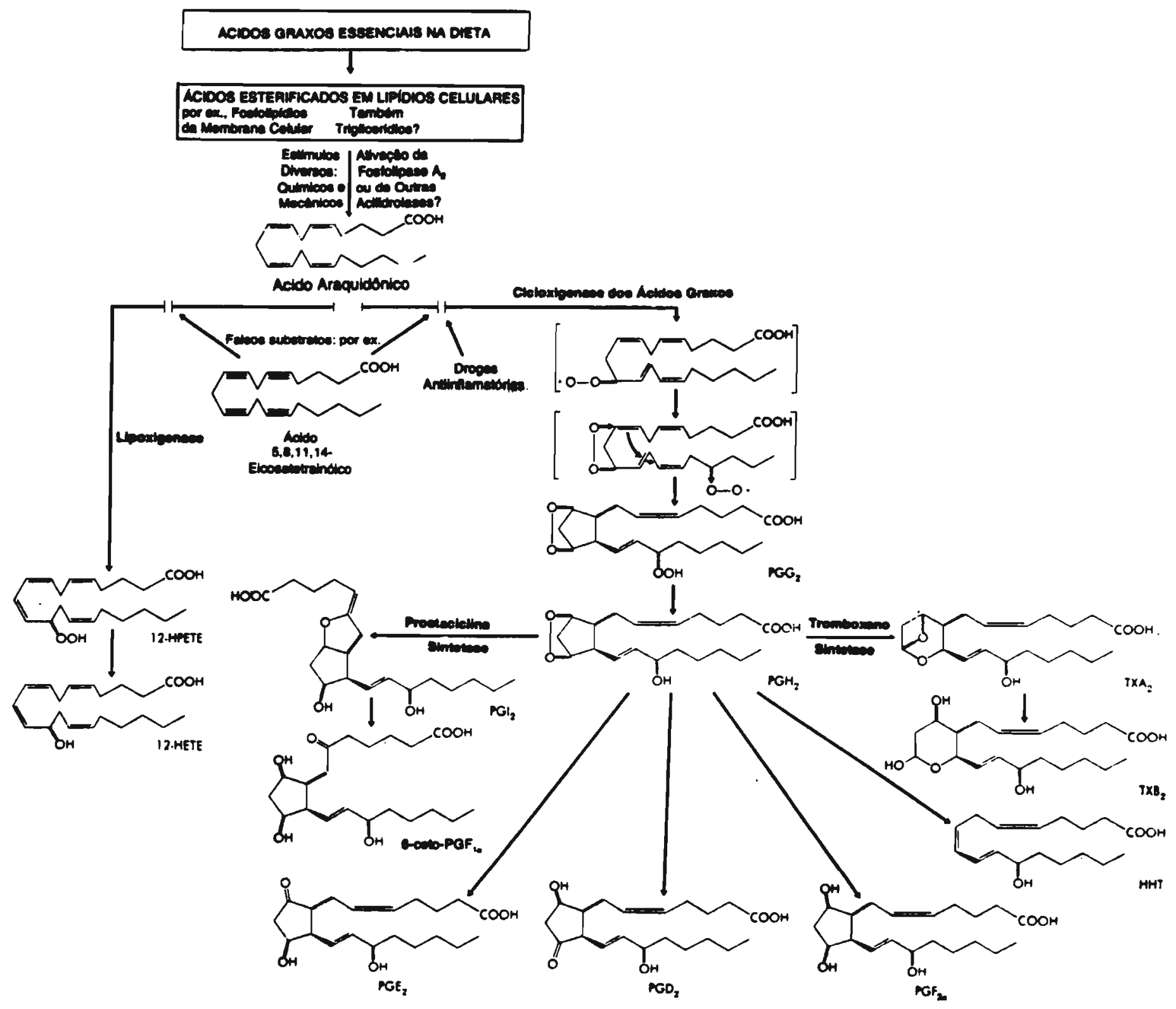

Figura 2 : Biossintese dos produtos do àcido araquidônico, precursor das prostaglandinas (MONCADA et alii, 1987 ). 
Portanto, a atividade analgésica é do tipo nãonarcótica, sendo de 4 a 30 vezes superior à do ácido acetilsalicilico. A ação inibitória é do tipo periférica e reversivel (ADAMS, 1973; ADAMS et alii, 1967).

\subsection{USOS CLINICOS:}

o ibuprofeno é utilizado no alivio de dores leves e moderadas, em condições tais como dismenorréia, dor pósoperatória, desordens reumáticas tais como osteoartrite, artrite reumatóide, espondilite anquilosante e outras desordens músculoesqueléticas. (FLOWER et alii, 1987; MARTINDALE, 1990; REFI, 1992).

Um dos maiores empregos do ibuprofeno na terapêtica é, sem dúvida, no tratamento sintomático da artrite reumatóide (WARD, 1984), doença sistêmica, caracterizada por uma inflamação crônica nas articulações.

JASANI et alii (1968), foram os pioneiros nas pesquisas que visavam o emprego do ibuprofeno na artrite reumatóide. Os pesquisadores administraram doses de $750 \mathrm{mg}$ do färmaco, $5 \mathrm{~g}$ de acido acetilsalicilico e $15 \mathrm{mg}$ de predinisona, além de placebo, em 9 voluntários portadores da doença, em intervalos de uma semana, durante um mês, e concluiam que o fármaco apresentava efeito analgésico e antiinflamatório nos pacientes estudados. 
ALTMAN (1984), revisou o uso do ibuprofeno na osteoartrite, uma doença degenerativa onde também está presente um processo inflamatório. A doença pode ser assintomática ou apresentar uma variedade não especifica e intermitente de sintomas, sendo a dor a principal razão pela qual se administram medicamentos. No seu trabalho de revisão, o autor analisou 28 estudos clinicos envolvendo o uso do ibuprofeno em casos de osteoartrite. Em alguns casos obteve resultados conflitantes, mas de uma maneira geral, os estudos indicavam que o fármaco era geralmente mais efetivo que outros agentes e que a tolerabilidade era muito melhor e os efeitos colaterais, poucos.

Em relação à dismenorréia, DAWOOD (1984) fez uma revisão sobre o tema. O distúrbio atinge um grande número de mulheres em todo o mundo, e é induzido pelo aumento da produçăo e liberação de prostaglandinas endometriais. O tratamento pode ser realizado com contraceptivos orais, que reduzem o volume total do fluido menstrual ou por um inibidor da sintese de prostaglandinas. Ainda neste artigo, o autor, analisando diversos trabalhos publicados até então, conclui que o ibuprofeno é efetivo na dismenorréia, e que este produz poucos ou não produz efeitos colaterais. Outros trabalhos demonstraram a superioridade do ibuprofeno sobre a aspirina (CORSON \& BOLOGNESE, 1978) e propoxifeno (MORRISON et alii, 1980) na dismenorréia.

Também na supressão da dor pós-operatória, o ibuprofeno é bastante empregado (COOPER, 1984 ; SLAVIC-SVIRCEV, 1984). 
DIONNE et alii (1983), estudou o emprego do ibuprofeno, administrado antes e após cirurgia para extração do terceiro molar, comparando-o com acetaminofem, acetaminofem + codeina e placebo. Os resultados indicaram que este esquema de prétratamento/tratamento era bastante eficiente em comparação com outras drogas estudadas, sem aumento dos efeitos colaterais.

FORBES et alii (1991), demonstraram que o efeito analgésico do ibuprofeno na dor pós-operatória em cirurgias orais pode ser incrementado, quando se combinam $200 \mathrm{mg}$ do fàrmaco com $100 \mathrm{mg}$ de cafeina. Além disto, a combinação mostrou-se significativamente superior em termos de inicio e duração do efeito.

2.4. REAÇõES ADVERSAS:

A ocorrência de efeitos colaterais durante 0 emprego do fármaco é limitada (BROOKS et alii, 1973; BUSSON, 1986; DRUG EVALUATIONS, 1991; REFI, 1992; ROYER et alii, 1984;).

Os efeitos adversos mais comuns ocorrem à nivel gastrintestinal, tais como indigestăo, náusea, dor epigástrica, diarréia, úlcera gastroduodenal, azia e desconforto abdominal (BROOKS et alii, 1973; FLOWER et alii, 1987; HANDBOOK OF NONPRESCPITION DRUGS, 1986; LANZA, 1984; REMINGTON, 1990). As lesões gástricas provocadas pelo fảrmaco parecem estar relacionadas com a inibiçăo da biossintese de prostaglandinas 
gàstricas. Estas são capazes de promover a secreção do muco citoprotetor e além disto, inibem a secreção àcida do estômago, prevenindo, desta forma, lesões na mucosa. Assim, a inibição de sua sintese pode tornar o estômago mais suceptivel à lesões (FLOWER et alii, 1987).

Também, devido à inibição da biossintese das prostaglandinas, podem ocorrer broncoespasmos em pacientes com história de asma, e decaimento da funçăo renal (HANDBOOK OF NONPRESCRIPTION DRUGS, 1986; REFI, 1992 ), embora este último não seja tão acentuado (BONNEY, 1986; FLOWER et alii, 1987).

Outros efeitos adversos relatados para o ibuprofeno são (HANDBOOK OF NONPRESCRIPTION DRUGS, 1986; MARTINDALE, 1989; REFI, 1992; REMINGTON, 1990):

- Dermatológicos: prurido, rash cutâneo, urticária, eritema multiforme;

- Sistema nervoso central: Depressão, confusão mental, cefaléia, insônia;

- Hematológicos: leucopenia, agranulocitose, redução da hemoglobina e do hematócrito;

- Outros: visão turva, insuficiência cardiaca congestiva, hipertensão, etc. 
As principais precauções com relação ao uso do ibuprofeno estão vinculadas à pacientes asmáticos, com história de ulcerações gàstricas, urticảria ou sensibilidade ao àcido acetilsalicilico. Também em pacientes com função renal, hepática ou cardiaca alteradas, deve-se ter atenção especial. Como recomendado para todos os AINEs, o ibuprofeno deve ser evitado durante a gravidez, sobretudo no primeiro trimestre, embora năo existam evidências com relação à sua teratogenicidade. (HANDBOOK OF NONPRESCRIPTION DRUGS, 1986; MARTINDALE, 1989; REFI, 1992.)

\subsection{FARMACOCINET ICA:}

O ibuprofeno é rapidamente absorvido apỏs administração oral, obtendo-se o pico de concentração plasmática em aproximadamente 1 ou 2 horas. A meia-vida plasmatica do fármaco é de cerca de 2 horas (DRUGDEX, 1992; FLOWER et alii, 1987).

O fármaco é metabolizado no figado, e os metabólitos excretados pela urina, sendo aproximadamente $1 \%$ sob a forma de droga livre. Não hà evidências de acumulação ou indução enzimàtica, e a excreção é virtualmente completada decorridos 24 horas após a última dose (DRUGDEX, 1992). Esta rápida metabolização e excreção parece explicar a baixa toxicidade do fảrmaco, se comparado à outros AINEs (BUSSON, 1986). 
2.6. POSOLOGIA:

A dosagem usual do fàrmaco é de 1200 à $3200 \mathrm{mg} / \mathrm{dia}$, em casos de osteoartrite e artrite reumatóide (DRUGDEX, 1992). Doses menores que $1200 \mathrm{mg}$ diariamente exercem, predominantemente, efeito analgésico, e a ação anti-inflamatória é evidenciada com doses superiores (BUSSON, 1986).

Assim, a dose recomendada para ação anti-inflamatòria é de 300-600 mg a cada periodo de 4-6 horas, até $2400 \mathrm{mg} / \mathrm{dia}$. A dose analgésica é 200-400 mg a cada pertodo de 4-6 horas, até $1200 \mathrm{mg} / \mathrm{dia}$. (HANDBOOK OF NONPRESCRIPTION DRUGS, 1986).

2.7. IBUPROFENO E PRESCRIÇO MEDICA:

O ibuprofeno foi introduzido na terapêutica em 1969, na Inglaterra e a partir de 1974, nos EUA (SITTIG, 1988). Considerando-se que o färmaco possui uma boa atividade analgésica e é considerado bastante seguro, em $1984 \circ$ Food and Drug Administration (FDA) dos EUA, decidiu pela liberação do ibuprofeno para venda sem prescrição médica, na concentração de $200 \mathrm{mg}$, para uso como analgésico (FLOWER et alii, 1987; HANDBOOK OF NONPRESCRIPTION DRUG, 1986). Na Inglaterra, a venda sem prescrição médica teve inicio em 1983 (PERRY et alii, 1987). 
2.8. FORMAS FARMACEUTICAS DO IBUPROFENO:

Sendo o ibuprofeno um AINE bastante seguro, e superior, em muitos aspectos à outros AINEs, o fármaco é comercializado no mundo inteiro, sendo inúmeras as especialidades farmacêticas existentes (MART INDALE, 1989).

o fármaco é comercializado principalmente sob a forma de comprimidos, embora exista também, sob a forma de cápsulas, supositórios, creme e grânulos (REFI, 1992). No mercado farmacêutico inglês, estão disponiveis cápsulas de ação prolongada do fármaco (MARTINDALE, 1989).

No Brasil, o ibuprofeno existe sob a forma de comprimidos de $300 \mathrm{mg}$ (ARTRIL 300 - FARMASA), comprimidos de 600 mg (DANILON - FRUMTOST; MOTRIN - RHODIA; ARTRIL 600 - FARMASA; IBUPROFENO - UNIAO QUIMICA) e supositórios de $600 \mathrm{mg}$ (DANILON ERUMTOST). Existe, também, em associação com o paracetamol (ALGIDANILON - FRUMTOST), sob a forma de comprimidos contendo $200 \mathrm{mg}$ de ibuprofeno e $300 \mathrm{mg}$ de paracetamol, e em associação com o fenoterol (FYMNAL - FARMASA), também sob a forma de comprimidos, contendo $200 \mathrm{mg}$ de ibuprofeno e $1,5 \mathrm{mg}$ de fenoterol (DEF, 1990). 
2.9. DISSOLUCAO DE COMPRIMIDOS DE IBUPROFENO:

Nos anos de 1984 e 1985, pesquisadores italianos (CHIARINI et alii, 1984; FINI et alii, 1984; FINI et alii, 1985) divulgaram uma série de resultados com relação ao estudo da solubilidade de diversos anti-inflamatórios não-esteroidais (AINEs), inclusive o ibuprofeno. Entre outros dados, os pesquisadores relataram que a solubilidade do fármaco à 25 oC era de apenas 11,3 mg/l (CHIARINI et alii, 1984), e que $\circ \mathrm{pH}$ em torno de 8 era o meio mais adequado para sua solubilização (FINI et alii, 1985).

Segundo CARCAMO (1981), "As limitadas possibilidades de dissolução de principios ativos relativamente insolúveis em àgua ou nos meios fisiológicos normais, tem sido, desde muito tempo, um problema para a indústria farmacêutica, sobretudo depois de se conhecer a influência da velocidade de dissolução sobre as caracteristicas de absorção destes." Sabendo-se que o ibuprofeno é um fármaco pouco solúvel em àgua, conclui-se que este deve apresentar problemas com relação à dissolução de suas formas farmacêticas sólidas. Além deste fato, a existência de um número muito grande de especialidades farmacêuticas contendo ibuprofeno em diversos paises (MARTINDALE, 1989), pode ocasionar problemas de bioequivalência.

Por outro lado, BRAMANTI et alii (1980) estudaram a difusão através de membrana artificial do cloranfenicol, 
sulfadimetosina, ketoprofeno e do ibuprofeno e concluiram que, para o ibuprofeno, quanto menor a granulometria deste, maior era sua absorção e que o fármaco era, dentre os pesquisados, o que apresentava a maior capacidade de atravessar a membrana artificial. Em outras palavras, isto significa que o fármaco é de dificil dissoluçăo, ou seja, o problema reside na liberação deste contido na forma farmacêtica, pois uma vez dissolvido, o principio ativo é rapidamente absorvido.

Assim, GILLESPIE et alii (1982), num estudo comparativo da biodisponibilidade de cinco diferentes preparações comerciais de ibuprofeno do mercado canadense (cápsulas de 200, 300 e $400 \mathrm{mg}$ e comprimidos de 300 e $400 \mathrm{mg}$ ), concluiram que os produtos eram equivalentes quanto ao total de fàrmaco absorvido. Porém, estes apresentavam diferenças significativas com relação à velocidade de absorçăo. Como a bioequivalência de formas farmacêuticas é baseada tanto na quantidade, quanto na velocidade de absorção, concluiram os autores que os produtos pesquisados eram inequivalentes.

Realizando um estudo de biodisponibilidade e testes de dissolução em dois lotes de uma mesma formulaçăo de comprimidos de ibuprofeno $200 \mathrm{mg}$, DASH et alii (1988), concluiram que estas eram bioequivalentes. Porém, no teste de dissolução, utilizandose o método da pá, à velocidade de $50 \mathrm{rpm}$, foram detectadas variações do tipo comprimido-comprimido e lote-lote. Entretanto, 
este fato parecia năo representar problemas do ponto de vista da biodisponibilidade.

WIESEND (1988), analisando 20 diferentes formulaçes comercials contendo 200,400 ou $600 \mathrm{mg}$ de ibuprofeno na Alemanha, concluiu que destas, duas năo satisfazlam o teste de dissolucão recomendado pela USP, e que as velocidades de dissoluçăo eram bastante variàveis entre as diversas formulaçôes.

ROMERO et alif (1988), após um estudo com oito formulaçóes de ibuprofeno, que foram submetidas à uma temperatura de $37{ }^{\circ} \mathrm{C}$ e $75 \%$ de umidade relativa e analisadas por três métodos diferentes de dissoluçăo, concluiam que comprimidos revestidos com acuicar eram particularmente sensiveis às condicões de estocagem, podendo apresentar diminuiçăo da eficácia clinica. Concluiam também, que o teste de dissoluçăo proposto pela USP, em comparaçăo com outros métodos, năo era capaz de discriminar as diferentes formulações e suas possiveis variações.

Porém, na Finlândia, PALVA et alii (1985), analisando três preparaç̧es comerciais do fármaco, concluiram que os produtos eram equivalentes em ensaios "in vivo", e que não eram observadas diferenças nos testes de dissoluçăo realizados nas formulações.

Em funçăo dos problemas que podem ocorrer nas formulaçơes, com relaçăo à biodisponibilidade, diversos 
pesquisadores tentam, utilizando variados recursos, melhorar a velocidade de dissolução destas. Assim, CHOW \& KARARA (1986), estudaram a complexação do ibuprofeno com B-ciclodextrina e obtiveram melhorias na solubilidade do fármaco. MURA et alii (1986, 1987a, 1987b), pesquisaram dispersões sólidas do ibuprofeno, com o mesmo objetivo, e alcançaram resultados satisfatórios com a uréia e diversos polietilenoglicóis. Outros exemplos são os trabalhos de IMAI et alii (1990), utilizando gelatina solúvel e KIMURA et alii (1991), com caseina e gelatina de baixo peso molecular.

HANNULA et alii (1989a, 1989b, 1989c) e MARVOLA et alii (1991), publicaram uma série de artigos que relatavam a influência de vàrios adjuvantes em formulações de càpsulas contendo ibuprofeno. Pesquisando a influência de alguns aditivos e o método de enchimento das cápsulas (manual ou automático), os autores concluiam, em relação aos adjuvantes, que o fosfato dicálcico, a lactose, a lactose "spray-dried" e a celulose microcristalina, quando usados como diluentes, produziam formulações aceitàveis, no caso de enchimento automático. Para o enchimento manual, lactose e fosfato dicalcico eram os melhores diluentes. Além disto, concluiam os autores, o amido de milho e a carboximetilcelulose, como desagregantes, afetavam negativamente a dissoluçăo das cápsulas (HANULA et alii, 1989c). Em outro trabalho, HANULA et alii (1989a), estudaram formulações de cápsulas de ibuprofeno contendo sacarose, celulose microcristalina, fosfato dicalcico ou amido de milho, e estes 
excipientes mais bicabornato de sòdio, em concentrações variàveis. Relataram valores entre 3 e 9 minutos para que as formulações tivessem $80 \%$ do principio ativo dissolvido.

HANULA et alii $(1989 \mathrm{c})$, também relataram o efeito do amido glicolato de sódio e da croscarmelose sódica como desagregantes. Concluiram, então, que estes eram mais efetivos quando, como diluente, utilizava-se o fosfato dicálcico (diluente insolúvel) e que quando o diluente era a celulose microcristalina, não havia necessidade do uso de desagregantes.

MARVOLA et alii (1991), estudaram três derivados da celulose: metilcelulose, celulose microcristalina e carboximetilcelulose sodica, na tentativa de obter uma formulaçăo de cápsulas de ibuprofeno que apresentassem caracteristicas de uma forma farmacêutica de ação prolongada. Concluiam que apenas a carboximetilcelulose sódica era capaz de controlar a dissolução do fármaco, porém, a correlação dos resultados obtidos in vivo e in vitro não era satisfatória.

2.10. FATORES DETERMINANTES DA DISSOLUCAO DE FORMAS FARMACEUTICAS SÓLIDAS :

Quando uma substância ativa é administrada oralmente, sob a forma solida, esta deve dissolver-se no conteúdo gastrintestinal para que a absorção sistêmica ocorra (figura 1). Geralmente, a velocidade de absorção do fảrmaco é determinada 
pela velocidade de dissolução da forma farmacêutica. Conseqüentemente, se é importante obter o pico do nivel sanguineo rapidamente, serà importante obter uma rảpida dissolução da forma farmacêtica. Nestes casos, o perfil de dissolução pode determinar o total de absorção do fảrmaco, bem como a velocidade de absorção. Então, a velocidade de dissolução deverà influenciar, diretamente, na eficàcia do medicamento (CARCAMO, 1981 ; DAVIS, 1972; GORDON et alii, 1990).

WAGNER (1969), numa revisão, abordou a questão dos fatores que podem influenciar a dissolução de formas farmacêuticas sólidas. Além dos fatores que podem interferir no ensaio in vitro de dissolução, tais como agitação, meio de dissolução empregado, temperatura, etc, temos ainda:

- Propriedades fisico-quimicas do fármaco;

- Formulação e tecnologia de fabricação;

- Idade da forma farmacêutica. 


\subsubsection{PROPRIEDADES FISICO-QUIMICAS DO FARMACO:}

2.10.1.1. POL IMORF ISMO:

O polimorfismo é uma propriedade que apresentam algumas substâncias solidas, de se cristalizarem em mais de uma estrutura cristalina (CARCAMO, 1981; GIBALDI, 1991; PARROT, 1970; STAVCHANSKY \& McGINIT, 1990). Este fenômeno pode acontecer quando, no processo de sintese da substância, ocorrem alterações tais como mudanças de solvente, variações na temperatura de cristalização, etc (CARCAMO, 1981; DAVIS, 1972; HIGUCHI, 1963).

As diferentes formas cristalinas de uma substância podem apresentar modificações em algumas de suas caracteristicas, tais como o ponto de fusão, espectro de absorção no infravermelho, solubilidade e velocidade de dissolução (CARCAMO, 1981; HIGUCHI, 1963; STAVCHANSKY \& MCGINIT, 1990).

Assim, formas polimorficas metaestàveis originam compostos com solubilidades mais altas que as formas termodinamicamente estáveis do mesmo composto. Portanto, as formas mais solùveis irão se dissolver mais rapidamente e serăo, consequientemente, mais rapidamente absorvidas (WAGNER, 1975). 
ROMERO et alii (1991), estudaram vàrias caracteristicas fisico-quimicas do ibuprofeno provenientes de cinco fabricantes diferentes. Em relação ao polimorfismo, concluiram os autores que - fenômeno não ocorria nas matérias-primas supridas por estes fabricantes.

2.10.1.2. SOLVATACAO:

Os fármacos podem apresentar-se sob a forma solvatada ou não-solvatada, manifestando assim, diferentes solubilidades, e conseqüentemente, diferentes velocidades de dissolução. A forma mais comum de solvatação é pela àgua (CARCAMO, 1981; DAVIS, 1972; STAVCHANSKY \& MCGINIT, 1990). Assim, formas anidras, monohidratadas, tri-hidratadas, entre outras, podem apresentar diferentes solubilidades (SHEFTER \& HIGUCHI, 1963).

Formas hidratadas, em geral, dissolvem-se mais lentamente que suas correspondentes formas anidras, o que pode ocasionar diferenças nos niveis sanguineos produzidos pelas duas formas (WAGNER, 1975).

- estado amorfo é o estado de mais alta energia, e portanto, é capaz de dissolver-se mais rapidamente que formas cristalinas do mesmo composto. Com base nisto, desenvolveu-se um recurso para melhorar a solubilidade de fármacos pouco solúveis denominado "co-precipitação", onde o fármaco e um polimero (polivinilpirrolidona ou polietilenoglicòis, por exemplo), são 
dissolvidos em um solvente juntamente com o fármaco, sendo o solvente evaporado. O produto resultante é sólido e geralmente dissolve-se mais rapidamente, devido à produção da forma amorfa do fàrmaco, além do aumento da sua àrea de superficie (WAGNER, 1975 ).

2.10.1.3. BASE LIVRE, ACIDO LIVRE OU FORMA SALINA:

A natureza quimica do fármaco exerce grande influência sobre a dissolução deste. Assim, àcidos fracos podem formar sais com bases fracas e estes podem ser mais ou menos solúveis que os compostos iniciais (WAGNER, 1975), ou seja, a velocidade de dissolução de um determinado sal é geralmente diferente do composto inicial. Sais de sodio e potássio de àcidos livres dissolvem-se mais rapidamente do que os ácidos livres, indiferentemente do $\mathrm{pH}$ do meio de dissolução (GIBALDI, 1991).

EINI et alii (1985), estabeleceram para uma série de àcidos carboxilicos antiinflamatórios não-esteroidais, inclusive - ibuprofeno, que suas formas salinas eram mais solúveis que as correspondentes formas acidas.

2.10.1.4. FORMAÇA DE COMPLEXOS:

A ocorrência de interações entre fármacos e excipientes numa formulação pode dar origem à uma diferença na liberação do principio ativo contido nesta. A maioria das interações que 
ocorrem nos medicamentos são do tipo "complexos moleculares", que são formados pela união de duas ou mais moléculas orgânicas, mediante ligações fracas ou por ponte de hidrogênio (CARCAMO, 1981). As interações mais frequentes parecem estar relacionadas com macromoléculas, tais como polivinilpirrolidona e polietilenoglicóis. HIGUCHI \& KURAMOTO (1954a), demonstraram que a polivinilpirrolidona é capaz de formar complexos com o sulfatiazol, salicilato de sodio, cloranfenicol e àcido mandélico. Também HIGUCHI \& KURAMOTO (1954b), evidenciaram a formação de complexo de polivinilpirrolidona com àcido paminobenzóico, àcido benzóico, ácido salicilico, àcido phidroxibenzóico, àcido m-hidroxibenzóico e fenobarbital.

Porém, a formação de complexos pode ser usada como recurso para melhorar a dissolução de fármacos, quando o complexo formado é mais solúvel. o caso de complexação de fármacos com ciclodextrinas (STARECHANSKY \& McGINITY, 1990). Este recurso jà foi estudado para o ibuprofeno por CHOW \& KARARA (1986).

2.10.2. FATORES TECNOLOGICOS:

2.10.2.1. INELUENCIA DOS COMPONENTES DA FORMULACAO:

2.10.2.1.1. INELUENCIA DOS DILUENTES:

Em geral, utilizam-se diluentes digeriveis na formulação de comprimidos para que não ocorra retardamento na 
liberação dos principios ativos (STAVCHANSKY \& McGINIT, 1990). Emprega-se entăo, vários tipos de carboidratos, embora substâncias insolùveis tais como carbonato de cálcio, hidróxido de aluminio coloidal e carbonato de magnésio também possam ser utilizadas (BANKER et alii, 1980; CARCAMO, 1981).

LEVY et alii (1963) estudaram este tipo de influência sobre a dissolução em formulações de àcido salicilico, preparadas por dupla compressăo. Observaram que o aumento do conteúdo do amido, utilizado como diluente, era capaz de aumentar a velocidade de dissolução proporcionalmente ao conteủdo deste na formulação.

2.10.2.1.2. INELUENCIA DOS DESAGREGANTES:

Os desagregantes geralmente exercem seu efeito devido à capacidade que possuem de aumentar seu volume com a àgua captada do meio em que se encontram (CARCAMO, 1981). Então, os diferentes desagregantes podem possuir uma maior ou menor capacidade de promoverem a desagregação, em função do seu mecanismo de ação (CID \& JAMINET, 1971).

Assim, KHAN \& RHODES (1971), estudaram cinco desagregantes diferentes. Concluiram que, com o amido glicolato de sòdio, os tempos de desagregaçăo eram menores e que a carboximetilcelulose proporcionava tempos de desagregaçăo maiores. Comparativamente, os tempos de desagregação obedeceram à 
seguinte ordem: carboximetilcelulose > amido > alginato > resina catiônica > amido glicolato de sódio.

2.10.2.1.3. INELUENCIA DOS AGLUTINANTES:

Os aglutinantes são adicionados às formulaçǒes de comprimidos para obter-se uma liga dos pós, tornando possivel a obtenção de grânulos, os quais podem ser mais facilmente compactados, dando origem aos comprimidos (BANKER et alii, 1980). Então, genericamente, pode-se dizer que a adição de um aglutinante terá como consequeencia um aumento no tempo de desagregação e na velocidade de dissoluçăo dos comprimidos (CARCAMO, 1981).

ITIOLA \& PILPEL (1986), JACOB \& PLEIN (1968), ALAM \& PARROT (1971) relatam estudos do efeito de aglutinantes sobre a desagregação e dissolução de comprimidos. De maneira geral, estes trabalhos indicam que aglutinantes tais como polivinilpirrolidona, goma de amido, gelatina e metilcelulose são mais adequados, pois năo retardam a desagregaçăo dos comprimidos. Indicam, também, que um aumento na concentraçăo do aglutinante é capaz de diminuir a velocidade de dissoluçăo da forma farmacêutica. 
2.10.2.1.4. INFLUENCIA DOS LUBRIFICANTES:

Em geral, os lubrificantes utilizados em formulações de comprimidos são substâncias hidrofóbicas e, quando utilizados em porcentagem elevada, podem diminuir a velocidade de dissolução destas (STAVCHANSKY \& McGINITY, 1990).

Assim, LEVY \& GUMTOW (1963), verificaram que lubrificantes insolúveis (estearato de magnésio, estearato de aluminio, acido esteàrico e talco) eram capazes de diminuir a velocidade de dissoluçăo de comprimidos de ácido salicilico, usados como modelo. Em contrapartida, lubrificantes solùveis, tais como laurilsulfato de sódio e oleato de sódio, não provocam este tipo de efeito indesejado.

2.10.2.1.5. INELUENCIA DE TENSIOATIVOS:

Os tensioativos podem ser adicionados à determinadas formulações com a finalidade de acelerar a dissolução destas. Em alguns casos podem ser utilizados como lubrificantes.

COOPER \& BRECHT (1957), foram os pioneiros na investigação do uso de tensioativos em comprimidos, com a finalidade de reduzir o tempo de desagregaçăo destes. Analisando os efeitos da adiçăo de vinte e un tipos de tensioativos, concluiram os autores que estes eram efetivos em vàrias formulações, em termos de redução do tempo de desagregação, 
principalmente se combinados à $0,2 \%$ na formulação com $10 \%$ de amido.

2.10.2.2. INELUENCIA DO METODO DE GRANULACAO EMPREGADO NA PRODUCAO:

O método de granulação empregado em determinada formulação poderà ditar a resistência mecânica deste, o que irà, conseqüentemente, influenciar na velocidade de dissolução da forma farmacêutica (CARCAMO, 1981).

Os comprimidos podem ser produzidos por granulação úmida, granulação seca ou por compressăo direta. Na granulação úmida, o aglutinante exercerà uma ação muito importante sobre a dissolução. Na granulação seca, a força de compressão utilizada na pré-compressão é um fator critico para a dissolução (WAGNER, 1969).

Embora SOLVANG \& FINHOLT (1970) tenham encontrado velocidades de dissolução semelhantes em comprimidos de fenobarbital sodico, tanto para aqueles produzidos por granulação seca ou úmida, os comprimidos produzidos por compressão direta do fármaco com celulose microcristalina apresentaram melhores resultados de dissolução. 
2.10.2.3. INELUENCIA DA GRANULOMETRIA:

Assim como as dimensões das particulas do principio ativo influenciam a velocidade de dissolução, também o tamanho dos grânulos a comprimir exercem, evidentemente, marcada influência.

Assim, LEVY et alii (1963), estudaram, entre outros fatores, o efeito do tamanho dos grânulos sob a dissolução de comprimidos de ácido salicilico, usados como modelo. Concluiam os autores que a velocidade de dissolução destes era menor para os comprimidos produzidos com grânulos menores.

Espera-se que, quanto menor for a particula, mais rápida serà a dissolução. Porém, deve-se considerar que transformações fisicas podem ocorrer durante o processo de compressão, ocasionando variações no tamanho granulométrico devido à ruptura ou aglomeração (CARCAMO, 1981). Isto foi demonstrado por GANDERTON et alii (1967), que, trabalhando com comprimidos de fenindiona, estabeleceram que, à valores de força de compressão baixos, a dissolução aumentava na medida em que diminuia-se o tamanho dos grânulos. Porém, com grânulos muito pequenos, e à valores de força de compressão mais elevados, a compactação ocasionava uma diminuição na velocidade de dissolução dos comprimidos. 
2.10.2.4. INFLUENCIA DA FORÇA DE COMPRESSAO:

A força de compressão utilizada no processo irá determinar a porosidade dos comprimidos, e esta determinará a velocidade com que a água irà penetrar no comprimido, promovendo a desagregação deste (PARROT, 1990).

HIGUCHI et alii (1953, 1954) foram os primeiros pesquisadores a estudarem a influência da força de compressão sobre as diversas caracteristicas de comprimidos, inclusive a desagregação. Nestes trabalhos, estabeleceu-se uma relação linear entre força de compressão e desagregação dos comprimidos estudados.

Porém, ocorrendo-se uma fragmentação dos grânulos, quando se aplica determinada pressão, a dissolução é mais ràpida se a força de compressão é aumentada, pois a fragmentação irá promover um aumento da superficie dos grânulos. Porém, se a ligação entre as particulas é o fenômeno predominante, o aumento da força aplicada origina um decréscimo na velocidade de dissolução (PARROT, 1990).

2.10.3. IDADE DA FORMA FARMACEUTICA:

Uma forma farmacêtica sólida, que apresente uma velocidade de dissolução adequada, pode, após decorrido um certo 
periodo de tempo, apresentar modificações no seu perfil de dissolução.

LEVY et alii (1963) observaram este efeito em comprimidos de àcido salicilico. Os grânulos destes comprimidos quando estocados à temperatura ambiente por 1,3 e 5 semanas produziam comprimidos com perfil de dissolução alterado, sendo menor o total dissolvido, em certo periodo de tempo, quando maior - tempo de estocagem.

E possivel encontrar na literatura diversos trabalhos onde os autores estudaram a questão do envelhecimento dos comprimidos e sua implicação na desagregação e na dissolução de formas farmacêuticas sólidas (ALAM \& PARROT, 1971; JACOB \& PLEIN, 1968; SEITZ \& FLESSLAND, 1965; WARD et alii, 1962), inclusive em relação ao ibuprofeno ( AULTON et alii, 1973; ROMERO et alii, 1988.) 


\section{CAPITULO III: OBJETIVOS}

São aqui apresentados os principais pontos a serem atingidos com a finalização deste trabalho. A proposição ora exposta é embasada nos dois capitulos anteriores. 
Pelo que foi aqui exposto até o presente momento, conclui-se que o ibuprofeno é um AINE bastante empregado na terapêtica, sendo utilizado, geralmente, sob a forma de comprimidos, nas concentrações de 200,400 e 600 mg. Entretanto, uma formulação contendo $200 \mathrm{mg}$ não està disponivel no mercado farmacêutico brasileiro (DEF, 1990).

Então, o objetivo deste trabalho é obter uma formulação de comprimidos de ibuprofeno na concentração de $200 \mathrm{mg}$, que deverá apresentar parâmetros fisico-quimicos de qualidade adequados e, principalmente, um adequado perfil de dissolução.

Em paralelo ao trabalho de obtenção da formulação, serà avaliada a influência dos excipientes sobre alguns dos parâmetros fisico-quimicos testados, bem como a influência do armazenamento, à diferentes temperaturas, sobre estes parâmetros, com a finalidade de se investigar possiveis modificações que possam inviabilizar a formulação, durante o periodo de armazenamento da mesma.

Resumidamente, os principais tópicos deste trabalho são:

- Estabelecer uma formulação adequada de comprimidos de ibuprofeno $200 \mathrm{mg}$; 
- Determinar a influência dos diversos excipientes utilizados sobre as caracteristicas fisico-quimicas das formulações e apontar as relações existentes entre as mesmas;

- Avaliar as transformações fisicas que podem surgir nas formulações, mediante um estudo de envelhecimento acelerado destas. 


\section{CAPITULO IV:}

\section{MATERIAIS E METODOS}

Neste capitulo é descrita a metodologia empregada na execução do presente trabalho, em cada uma de suas etapas : (1) o preparo das formulações; (2) as análises executadas e sua interpretação e (3) a verificação da estabilidade fisica das formulações.

Os equipamentos e reagentes utilizados são indicados à medida em que são expostas as etapas nas quais foram empregados. 
4.1. PREPARO DOS COMPRIMIDOS:

4.1.1. PLANEJAMENTO ESTATISTICO DAS FORMULAÇõES:

Um processo de otimização requer a produção de uma série de formulações, nas quais varia-se a concentração ou o tipo de excipiente. Após uma anàlise comparativa é possivel eleger-se a formulação que apresenta as melhores caracteristicas, ou o maior número de caracteristicas desejảveis (BOLTON, 1984).

No presente trabalho, para a obtenção das diferentes formulações, utilizou-se o PROJETO FATORIAL (BENNETT \& FRANKLIN, 1954; BOLTON, 1984; DUCKWORTH , 1968). Este projeto apresenta uma série de vantagens, entre as quais cita-se:

- Estimativa do efeito de diversos fatores simultaneamente, de maneira planejada e controlada;

- Estimativa de efeitos médios e interaçoses.

O uso do PROJETO FATORIAL em Tecnologia Farmacêutica vem ganhando espaço nos últimos anos e é possivel encontrar na literatura publicações relatando sua utilização em estudos de estabilidade (BOLTON, 1983), interação droga-excipiente (PLAIZIER-VERCAMMEN \& De NEVE, 1981), entre outros. 
O PROJETO FATORIAL considera o efeito de vàrios fatores (ex.: concentração do excipiente, tipo de excipiente, pH, temperatura, etc.) a diversos niveis (ex.: duas concentrações do excipiente: uma baixa e outra alta). Porém, isto demanda um volume muito grande de experimentos, pois o número destes é dado por:

$$
\mathrm{Nn}
$$

onde: $\mathrm{N}=$ número de niveis

$\mathrm{n}=$ número de fatores estudados

No presente trabalho foram testados os seguintes excipientes:

- Diluente: amido

- Aglutinantes: Polivinilpirrolidona (PVP) e goma de amido;

- Desagregantes: mistura amido/celulose microcristalina (CM) e mistura amido/explosol;

- Lubrificantes: estearato de magnésio (anti-aderente) e talco (deslizante).

Os excipientes, então, formam os diversos fatores estudados, e ficaram assim agrupados com seus respectivos niveis, como demonstrado na tabela 1. 
Tabela 1 : Fatores estudados e seus respectivos niveis.

\begin{tabular}{ccc}
\hline FATOR & NIVEL + & NIVEL - \\
\hline$X_{1}$ (amido) & $35 \mathrm{mg}$ & $25 \mathrm{mg}$ \\
$\mathrm{X}_{2}$ (aglutinante) & goma* & PVP** \\
$X_{3}$ (desagregante) & amido/explosol & amido/CM*** \\
$X_{4}$ (talco) & $7 \mathrm{mg}$ & 0 \\
$X_{5}$ (estearato)**** & $8 \mathrm{mg}$ & $3 \mathrm{mg}$ \\
\hline
\end{tabular}

* goma de amido

** polivinilpirrolidona

*** celulose microcristalina

**** estearato de magnésio

Portanto, neste caso seriam necessários $2^{5}$ experimentos, ou seja, seria necessàrio produzir 32 formulações diferentes de comprimidos. Preferiu-se, então, adotar um PROJETO FATORIAL ERACIONADO (COCHRAN, \& COX, 1957; DUCKWORTH, 1968 ; KEMPTHORNE, 1952), mais especificamente $1 / 4$ de 25 , o que resulta num total de apenas 8 experimentos (formulações), representadas na tabela 2 . 
Tabela 2 : Eormulaçőes obtidas a partir do projeto fatorial fracionado $\left(1 / 4\right.$ de $\left.2^{5}\right)$.

\begin{tabular}{|c|c|c|c|c|c|}
\hline & $\begin{array}{c}X_{1} \\
A M I D O)\end{array}$ & $\frac{\mathrm{X}_{2}}{\text { (AGLUTINANTE) }}$ & $\begin{array}{c}\mathrm{X}_{3} \\
(\mathrm{DESAG} .)^{*}\end{array}$ & $\begin{array}{c}\mathrm{X}_{4} \\
(\mathrm{TALCO})\end{array}$ & $\begin{array}{c}X_{5} \\
(\text { ESTEARATO })^{* * *}\end{array}$ \\
\hline$I$ & - & $\overline{-}$ & - & + & + \\
\hline II & + & - & - & - & - \\
\hline I I I & - & + & - & - & + \\
\hline IV & + & + & - & + & - \\
\hline$v$ & - & - & + & + & - \\
\hline$V I$ & + & - & + & - & + \\
\hline VII & - & + & + & - & - \\
\hline VIII & + & + & + & + & + \\
\hline
\end{tabular}

* Desagregante

** Estearato de magnésio

A montagem da tabela 2 obedece à seguinte ordem: a primeira coluna obtêm-se alternando os sinais "-" e "+" , a segunda, dois sinais "-" e dois sinais "+", a terceira, quatro sinais "-" e quatro sinais "+", e as seguintes são obtidas multiplicando-se a primeira coluna pela segunda (obtendo-se a quarta coluna) e a primeira coluna pela terceira (quinta coluna).

Substituindo-se os sinais pelas quantidades de excipientes e organizando-os nas diferentes categorias, obtemos as 8 formulaçðes, com seus excipientes e respectivas proporções, expressos em mg, que encontram-se descritos na tabela 3. 
Tabela 3 : Eormulações produzidas, seus excipientes e respectivas quantidades utilizadas.

\begin{tabular}{|c|c|c|c|c|c|c|c|c|}
\hline$n_{-}^{0} d e$ ordema & $!$ & 11 & m! & IV & $V$ & VI & VII & VII! \\
\hline$n^{\circ}$ do lote 81 & 7 & 5 & 6 & 4 & 8 & 2 & 1 & 3 \\
\hline ibuprofeno & 200 & 200 & 200 & 200 & 200 & 200 & 200 & 200 \\
\hline agido & 25 & 35 & 25 & 35 & 25 & 35 & 25 & 35 \\
\hline aglutinante & $\begin{array}{c}\text { PVP } \\
7\end{array}$ & $\begin{array}{c}\text { PUP } \\
7\end{array}$ & $\begin{array}{c}\text { goua } \\
7\end{array}$ & $\begin{array}{c}\text { goad } \\
7\end{array}$ & $\begin{array}{c}\text { PYP } \\
7\end{array}$ & $\begin{array}{c}\text { PIP } \\
7\end{array}$ & $\begin{array}{c}\text { gona } \\
7\end{array}$ & $\begin{array}{c}\text { goed } \\
?\end{array}$ \\
\hline desagregante & $\begin{array}{l}30 \text { ido } \\
0 \\
20\end{array}$ & $\begin{array}{l}\text { anido } \\
\mathrm{CM} \\
20\end{array}$ & $\begin{array}{l}\text { anido } \\
\mathrm{CH} \\
20\end{array}$ & $\begin{array}{l}\text { anido } \\
\text { Cy } \\
20\end{array}$ & $\begin{array}{c}\text { anido } \\
\text { explosol } \\
20\end{array}$ & $\begin{array}{l}\text { anido } \\
\text { explosol } \\
20\end{array}$ & $\begin{array}{c}\text { anida } \\
\text { explosol } \\
20\end{array}$ & $\begin{array}{c}\text { anido } \\
\text { explosol } \\
20\end{array}$ \\
\hline 53160 & 7 & 0 & 0 & 7 & 7 & 0 & 0 & 7 \\
\hline estearato de $\mathrm{Mg}$ & 9 & 3 & 9 & 3 & 3 & 8 & 3 & 9 \\
\hline $\begin{array}{c}\text { 1istura } \\
\text { lactose/CM } \\
(4 / 1)^{21 .}\end{array}$ & 83 & 85 & 90 & 78 & 88 & $B O$ & 95 & 73 \\
\hline
\end{tabular}

LEgENDA: PUP = polivinilpirrolidona; goaa = qona de anido; $C M=$ celulose acrocristalina; estearato de Mg = Estearato de agnésio;

* Ordem para cálculo das formulações.

** Ordem de preparo das formulaçǒes, obtido por sorteio.

*** Utilizada em quantidade suficiente para obtenção de comprimidos com peso final de $350 \mathrm{mg}$.

Com relação ao critério de escolha dos excipientes, procurou-se utilizar aqueles que, do ponto de vista teórico, pudessem auxiliar, de uma forma ou de outra, na dissolução dos comprimidos. Isto em função dos já relatados problemas apresentados pelo fàrmaco. Além disto, para os excipientes utilizados, não encontrou-se na literatura nenhuma interaçăo indesejada (KARARLI et alii, 1989). 
Em resumo, as formulações, seus excipientes e suas quantidades encontram-se descritos na tabela 4.

Tabela 4 : Excipientes utilizados em cada formulação e suas respectivas proporções.

\begin{tabular}{lccccccc}
\hline lote & amido & lactose & C.M. & explosol & PVP & talco & est. \\
\hline 1 & 47 & 76 & 19 & 5 & - & - & 3 \\
2 & 50 & 64 & 16 & 5 & 7 & - & 8 \\
3 & 57 & 58,4 & 14,6 & 5 & - & 7 & 8 \\
4 & 57 & 62,4 & 20,6 & - & - & 7 & 3 \\
5 & 50 & 68 & 22 & - & 7 & - & 3 \\
6 & 47 & 72 & 23 & - & - & - & 8 \\
7 & 40 & 66,4 & 21,6 & - & 7 & 7 & 8 \\
8 & 40 & 70,4 & 17,6 & 5 & 7 & 7 & 3 \\
\hline
\end{tabular}

LEGENDA: C.M. = celulose microcristalina; PVP = polivinilpirrolidona; est. = estearato de magnésio.

4.1.2. PRODUCAO DOS LOTES:

Os diferentes lotes foram produzidos pelo processo de granulação "à úmido" (BANKER \& ANDERSON, 1986). As etapas deste processo estão representadas, esquematicamente na figura 3 . 
MATÉRIAS-PRIMAS

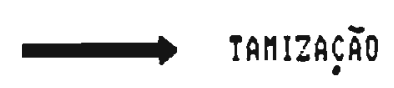

$\longrightarrow$ HOMOGENEIZAÇÃO

$\longrightarrow$ UMECTAÇÃO

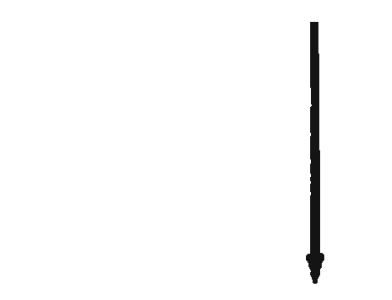

COMPRESST̃O

GALIBRACÃO

SECAGEN

GRANULACẼOO

Figura 3 : Esquema das etapas do processo de granulação úmida aqui utilizado.

Foram produzidos 350 gramas em cada lote, total suficiente para obter 1000 comprimidos, de $350 \mathrm{mg}$ cada.

4.1.2.1. MATERIAS-PRIMAS :

Todas as matérias-primas aqui utilizadas correspondiam ao grau farmacêtico, seguindo as especificaçŏes da USP XXII (1989), e encontram-se abaixo discriminadas:

- Ibuprofeno;

- Amido ;

- Lactose;

- PVP K-90;

- Celulose microcristalina;

- Explosol;

- Estearato de magnésio;

- Talco;

- Alcool etilico 95\% . 
4.1.2.2. TAMISACAO:

As diferentes matérias-primas constituintes das formulações foram tamisados utilizando-se um tamis número 15 .

4.1.2.3. HOMOGENEIZACAO:

Após a tamisação, os pós constituintes da formulação (exceto os desagregantes, aglutinante e lubrificante(s)), eram levados à um misturador bi-cônico MULTIPEX DUA4/2 (Apex Engeneering industries LTD), cuja velocidade foi ajustada na posição 8 (aproximadamente $35 \mathrm{rpm}$ ), por um periodo de 15 minutos.

4.1.2.4. UMECTAÇAO:

Finalizada a homogeneização, os pós eram, então, recolhidos em bandejas de aço inoxidável e então incorporado o aglutinante. Com o auxilio das mãos, devidamente protegidas por luvas de borracha, estes eram misturados até obtenção do "ponto ideal", ou seja até que a massa obtida, quando comprimida pelas mãos, quebrava-se sem esfarelar (BANKER \& ANDERSON, 1986).

4.1.2.5. GRANULAÇAO:

A massa obtida era, então, passada através de um granulador rotativo, (FABBE-PRIMAR INDUSTRIAL LTDA), utilizando-se 
malha de abertura de $1,5 \mathrm{~mm}$, sendo $\circ$ granulado recolhido em bandejas de aço inoxidàvel forradas com papel.

4.1.2.6. SECAGEM:

As bandejas com os granulados foram colocadas em estufa com circulação forçada de ar (FABBE-PRIMAR INDUSTRIAL LTDA).

A temperatura foi ajustada para $40^{\circ} \mathrm{C}$ e 0 tempo de secagem foi de 15 horas. Esta temperatura relativamente baixa foi necessària, visto que o ibuprofeno é um composto facilmente sublimável (ERTEL et alii, 1989).

4.1.2.7. CALIBRAÇAO DO GRANULADO:

Decorrido o tempo estipulado para a secagem do granulado, este era novamente passado através de malha de abertura $2 \mathrm{~mm}$ em granulador rotativo, sendo recebido em saco plástico e então levado ao misturador bi-cônico. Neste momento, incorporava-se os desagregantes e o(s) lubrificante(s). 0 equipamento era ajustado na posição 8 de velocidade, deixado-o funcionar por 15 minutos.

4.1.2.8. COMPRESSAO:

Estando o granulado convenientemente preparado, iniciava-se o processo de compressåo. Este foi executado em 
máquina excêntrica FABBE, utilizando-se um jogo de punções de 12 mm de diâmetro e matriz adequada.

4.2. ANALISES FISICO-QUIMICAS:

4.2.1. ASPECTO:

Os comprimidos eram observados à olho nu, para a descrição das suas caracteristicas apresentadas à superficie, tais como cor, odor, rugosidades, porosidades, etc.

4.2.2. PESO MEDIO:

Utilizando-se uma balança de precisão METTLER H15, foram pesados 10 comprimidos de cada lote.

4.2.3. DUREZA, DIAMETRO E ESPESSURA:

Estas anàlises foram executadas simultaneamente, utilizando-se um SISTEMA DE TESTE DE COMPRIMIDOS FARMATEST PTB 311 (Scientific Instruments \& Technology Corporation). Foram tomados 10 comprimidos e os resultados apresentados referem-se à média destes. 
4.2.4. FRIABILIDADE:

Para a apreciação da friabilidade dos comprimidos, empregou-se a metodologia descrita pela Farmacopéia brasileira (EB IV , 1988). Foram tomados 10 comprimidos em cada anàlise. 0 equipamento utilizado, marca ETICA, atendia as especificações da citada farmacopéia.

4.2.5. TEMPO DE DESAGREGAÇAO:

Para este ensaio utilizou-se a metodologia e o equipamento (ETICA) especificados pela USP XXII (1989) E EB IV (1988). Foram analisados cinco comprimidos de cada formulação e considerou-se o final do ensaio, o instante em que não mais era observado, sobre a tela do equipamento, qualquer fragmento do comprimido. Os resultados foram expressos em minutos e correspondem à média dos valores obtidos para cinco comprimidos testados.

4.2.6. DISSOLUÇA:

Neste trabalho, procurou-se avaliar não apenas 0 percentual dissolvido durante um certo periodo de tempo, mas sim - perfil de dissolução apresentado pela formulação.

o equipamento utilizado (HANSON RESEARCH CORP.) é descrito na USP XXII (1989) e FB IV (1988). Utilizou-se ainda, o 
método 2 (pà) e como meio de dissolução, tampão fosfato pH 7,2 (900 $\mathrm{ml}$ ), sendo analisados, de cada lote, 3 comprimidos. Foram tomadas amostras de $10 \mathrm{ml}$, à $1,5,10,15,20$ e 30 minutos, sendo que, para cada tomada de amostra, fazia-se a reposiçăo com igual volume de tampão fosfato à cuba de dissolução. Após a filtração em papel Whatmam 42, era então, tomada uma aliquota do filtrado e esta diluida convenientemente em tampão fosfato. As leituras foram realizadas em espectrofotômetro digital INCIBRAS MF 200 à $221 \mathrm{~nm}$ (USP XXII, 1989). A concentração foi calculada pela equação obtida através de reta de calibraçăo (Figura 4) convenientemente obtida em espectrofotômetro BECKMAN DU-70.

Os reagentes utilizados neste ensaio foram os seguintes:

- Hidróxido de sódio PA - Carlo Erba;

- Eosfato monobásico de potássio PA - E. Merck;

- Agua degaseificada, obtida por aquecimento à ebulição por 30 minutos .;

- Ibuprofeno padrão secundàrio, gentilmente cedido pela RHODIA EARMA LTDA. 


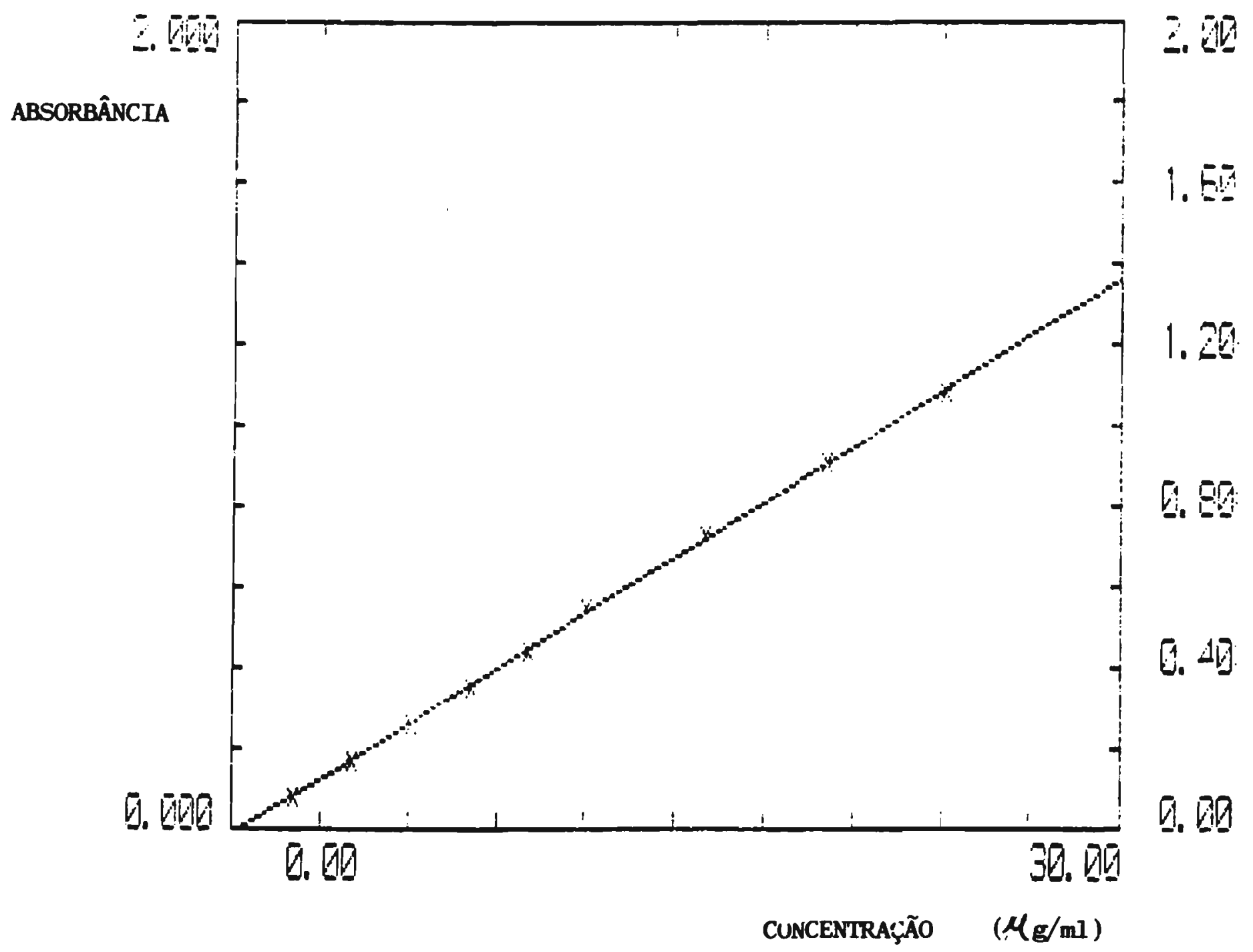

Figura 4 : Reta de calibração para o ibuprofeno. Meio: tampăo fosfato $\mathrm{pH}$ 7,2; Comprimento de onda: $221 \mathrm{~nm}$. Coeficiente de correlaçăo linear = 0,9999; Coeficiente angular $=0,0460$. 
4.2.7. TEOR DE IBUPROEENO:

Para verificação do teor de ibuprofeno nas diferentes formulações, utilizou-se o método espectrofotométrico. A técnica utilizada foi a seguinte: foram tomados, para cada lote, 10 comprimidos e estes, com auxilio de gral e pistilo, reduzidos à pó. Pesou-se cerca de 0,2 g deste pó e transferiu-se para um balăo volumétrico de $100 \mathrm{ml}$, diluindo-se com solução de hidróxido de sódio $0,1 \mathrm{~N}$ e deixando-se, antes do acerto do volume, em ultra-som (THORNTOM T14) por cinco minutos. Após o acerto de volume, a solução era filtrada em papel Whatman 42 e dai tomada uma aliquota de $5 \mathrm{ml}$ e novamente diluida para $100 \mathrm{ml}$ com solução de hidróxido de sòdio 0,1 N. Entăo, utilizando-se um espectrofotômetro INCIBRAS MF 200 foi feita a leitura em UV a 264 nm (CLARKE'S ISOLATION AND IDENTIFICATION OF DRUGS, 1986). A concentração da amostra foi obtida com auxilio de padrão convenientemente diluido, através da fórmula:

$$
C_{A}=\frac{L_{A}}{L_{P}} \times C_{P}
$$

onde: $C_{A}=$ concentração da amostra

$L_{\mathbf{A}}=$ leitura da amostra

$\mathrm{C}_{P}=$ concentração do padrão

$L_{P}=$ leitura do padrão

Para todos os lotes, as análises foram executadas em duplicata e os valores apresentados referem-se à média destes. 
Os reagentes utilizados foram:

- Hidróxido de sódio PA - Carlo Erba;

- Agua degaseificada, obtida por aquecimento à ebulição por 30 minutos;

- Ibuprofeno padrão secundàrio, gentilmente cedido pela RHODIA FARMA LTDA.

4.3. ANALISE E INTERPRETACAO DOS RESULTADOS OBTIDOS:

Com a finalidade de facilitar a interpretação e visualização dos resultados das análises executadas nas diversas formulações, recorreu-se ao uso de micro computador tipo IBM 386 SX, utilizando-se o programa STATGRAEICS.

Os resultados foram interpretados por uma analise exploratória e por intermédio de um estudo de efeitos.

\subsubsection{ANALISE EXPLORATÓRIA:}

Através da construção de diagramas multivariados, é possivel visualizar, de maneira global, o comportamento das diferentes formulações. Um diagrama multivariado é apresentado na Figura 5. Pode-se observar que cada eixo representa um ensaio, e assim è possivel avaliar, para uma mesma formulação, e ao mesmo tempo, os resultados referentes à dureza, friabilidade, desagregação e dissoluçăo. Atribuindo-se valores ideais (teóricos) à estes ensaios, obtém-se um diagrama multivariado 
ideal, e este é comparado com os diagramas das diversas formulaçōes produzidas. A formulaçăo que apresentar o diagrama multivariado mais assemelhado ao diagrama multivariado ideal, terá sido a mais adequada, do ponto de vista destas análises.

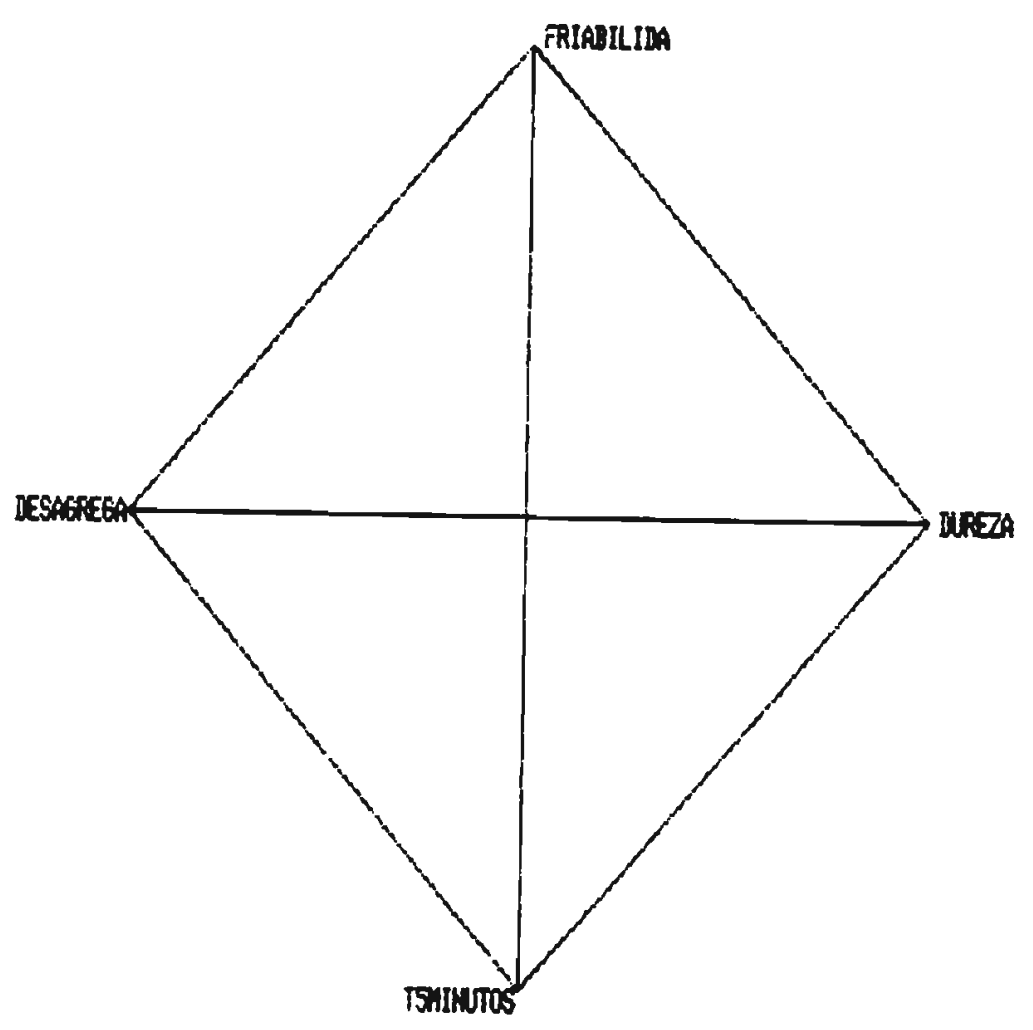

Eigura 5 : Diagrama multivariado onde foram plotados os parâmetros friabilidade (FRIABILIDA), tempo de desagregação (DESAGREGA), total dissolvido do fármaco após 5 minutos (T5MINUTOS) e dureza dos comprimidos (DUREZA). 
4.3.2. ESTUDO DOS EFEITOS:

Os diversos fatores estudados $X_{1}, X_{2}, X_{3}, X_{4}$ e $X_{5}$, respectivamente, amido, aglutinante, desagregante, talco e estearato de magnésio, foram avaliados com relação à sua influência sobre os ensaios de dureza, friabilidade, desagregação e dissolução.

Os efeitos podem ser facilmente estimados através do uso do programa STATGRAFICS. Entrando-se com os dados obtidos nos ensaios, e os seus niveis ("+" ou "-") dos diversos fatores estudados, são obtidos os coeficientes de regressão múltipla, os erros padrões e os valores dos niveis descritivos ( $p$ ) para cada tipo de ensaio. Para que seja considerada significativa, determinada interação deve satisfazer a dois requisitos básicos:

- O coeficiente de regressão múltipla deve ser muito maior que o erro padrão do ensaio e,

- O valor do nivel descritivo deve ser menor que 0,05 .

Entåo, com os valores das constantes e dos coeficientes de regressão múltipla das interações significativas, obtém-se equaçð̃es nas quais encontram-se descritas estas interações. 
4.4. ESTABILIDADE FISICA DAS FORMULAÇÕES:

Com o finalidade de observar as alterações fisicas que podem ocorrer nas diferentes formulações, utilizou-se uma metodologia similar à adotada por ALAM e PARROTT (1971). Os autores trabalharam com comprimidos de hidroclorotiazida e seus objetivos eram os mesmos: verificar o efeito do armazenamento sobre as caracteristicas fisicas daqueles comprimidos.

No presente trabalho, para o estudo da estabilidade fisica das formulações, partiu-se de três informações básicas:

- o ponto de fusão do ibuprofeno está situado na faixa de $75-77$ OC (MERCK INDEX, 1989);

- O composto é sublimável (ERTEL et alii, 1990);

- O composto é passivel de sofrer um processo de degradação por oxidação, que é influenciado pela temperatura (DONDONI et alii, 1986 ).

Então, foram escolhidas três temperaturas de trabalho: ambiente, 37 o C (em estufa) e 50 o C (em estufa). Os comprimidos, de cada lote separadamente, foram colocados em numero suficiente em placas de Petri e levadas às estufas. 
Além das anàlises iniciais, executadas após a produção de cada lote, foram executadas anàlises à 30 dias e à 60 dias após a produção e posterior armazenamento dos comprimidos. Esquematicamente, o calendàrio de anàlises foi o seguinte:

- INICIAL : após a produção do lote;

- TEMP. AMBIENTE : 30 e 60 dias após a produção do lote;

- 37 으 (ESTUEA) : 30 e 60 dias de armazenamento;

- $50{ }^{\circ} \mathrm{C}$ (ESTUFA) : 30 e 60 dias de armazenamento.

Após o término do prazo estipulado, os comprimidos eram retirados das estufas $\left(37{ }^{\circ} \mathrm{C}\right.$ e 50 o C ), deixando-os atingir a temperatura ambiente, sendo então analisados. Os ensaios executados foram:

- Aspecto;

_ Dureza, espessura e diâmetro;

_ Eriabilidade;

- Tempo de desagregação. 


\title{
CAPITULO $\mathrm{V}=$ RESULTADOS
}

\begin{abstract}
Os resultados oriundos do presente trabalho são aqui expostós em forma de tabelas, graficos e figuras e estão subdivididos em duas partes:
\end{abstract}

I: Analise fisico-quimica das formulações e sua interpretação;

II: Ensaio de estabilidade fisica das formulações. 
PARTB I :

ANALISE FISICO-QUIHICA DAS FORMULACÕES

E SUA INTERPRETACAO. 
5.1.1. ASPECTO:

De modo genério, pode-se dizer que em todas os lotes produzidos, os comprimidos apresentaram aspecto uniforme, sem alterações aparentes, excetuando-se os lotes de números 1,2 e 4 . Em função da aderência dos pỏs às punções, alguns comprimidos destes lotes apresentaram-se marcados, exibindo irregularidades à superficie.

5.1.2. PESO MEDIO:

Os resultados dos pesos-médios das formulações, com seus respectivos desvios padrões, são apresentados na Tabela 5.

Tabela 5 : Valores de peso médio dos comprimidos e respectivo desvio-padrão obtidos dos 8 lotes.

\begin{tabular}{ccc}
\hline LOTE & PESO MEDIO $(\mathrm{mg})$ & DESVIO PADRAO \\
\hline 1 & 0,3429 & 0,0062 \\
2 & 0,3483 & 0,0060 \\
3 & 0,3560 & 0,0050 \\
4 & 0,3577 & 0,0072 \\
5 & 0,3526 & 0,0054 \\
6 & 0,3462 & 0,0071 \\
7 & 0,3520 & 0,0104 \\
8 & 0,3536 & 0,0070 \\
\hline
\end{tabular}


5.1.3 DUREZA, FRIABILIDADE, DIAMETRO E ESPESSURA DOS COMPRIMIDOS:

Os resultados destas análises encontram-se descritos na Tabela 6 .

Tabela 6 : Resultados de dureza, friabilidade, diâmetro e espessura dos comprimidos dos 8 lotes.

\begin{tabular}{ccccc}
\hline LOTE & $\begin{array}{c}\text { DUREZA } \\
(\mathrm{N})\end{array}$ & $\begin{array}{c}\text { FRIABILIDADE } \\
(\%)\end{array}$ & $\begin{array}{c}\text { DIAMETRO } \\
(\mathrm{mm})\end{array}$ & $\begin{array}{c}\text { ESPESSURA } \\
(\mathrm{mm})\end{array}$ \\
\hline 1 & 31,47 & 1,72 & 11,988 & 2,756 \\
2 & 43,94 & 0,37 & 11,983 & 2,806 \\
3 & 26,23 & 2,95 & 11,994 & 2,807 \\
4 & 31,86 & 3,79 & 11,988 & 2,814 \\
5 & 44,51 & 0,18 & 11,966 & 2,798 \\
6 & 26,71 & 0,61 & 11,960 & 2,675 \\
7 & 32,49 & 0,34 & 11,952 & 2,692 \\
8 & 40,49 & 0,25 & 11,960 & 2,698 \\
\hline
\end{tabular}

5.1.4. ENSAIOS DE DESAGREGAÇO, DISSOLUÇO E TEOR DOS COMPRIMIDOS :

Os valores obtidos no ensaio do tempo de desagregaça, de dissolução, bem como o teor dos comprimidos, encontram-se descritos na Tabela 7. 
Tabela 7 : Resultados do tempo de desagregaçăo, total dissolvido após 5 minutos $\left(T_{5 m 1 n}\right)$ e teor de ibuprofeno dos comprimidos dos 8 lotes produzidos.

\begin{tabular}{|c|c|c|c|}
\hline LOTE & $\begin{array}{c}\text { TEMPO DE DESAGREGAÇAO } \\
\text { (MINUTOS) }\end{array}$ & $\begin{array}{c}\text { T } 5 m 1 n \\
(\%)\end{array}$ & $\begin{array}{r}\text { TEOR } \\
(\%)\end{array}$ \\
\hline 1 & 1,600 & 88,12 & 110,43 \\
\hline 2 & 17,37 & 42,01 & 102,45 \\
\hline 3 & 0,610 & 77,02 & 101,54 \\
\hline 4 & 0,410 & 85,59 & 102,44 \\
\hline 5 & 87,87 & 8,490 & 101,50 \\
\hline 6 & 0,770 & 88,12 & 103,67 \\
\hline 7 & 153,5 & 6,070 & 111,46 \\
\hline 8 & 32,04 & 20,56 & 112,93 \\
\hline
\end{tabular}

Na Tabela 8, são apresentados, além do total dissolvido em 5 minutos $\left(T_{5 m 1 n}\right)$, o total dissolvido em 15 minutos $\left(T_{15 m 1 n}\right)$ e 30 minutos $\left(\mathrm{T}_{30 \mathrm{~m} 1 \mathrm{n}}\right)$. 
Tabela 8 : Total dissolvido de ibuprofeno após 5 minutos (T $5 m 1 n)$, após 15 minutos $\left(T_{15 \mathrm{~m} 1 \mathrm{n}}\right)$ e após 30 minutos $\left(\mathrm{T}_{30 \mathrm{~m} 1 \mathrm{n}}\right)$.

\begin{tabular}{cccc}
\hline LOTE & $\begin{array}{c}\text { T5MIN } \\
(\%)\end{array}$ & $\begin{array}{c}\text { T 15MIN } \\
(\%)\end{array}$ & $\begin{array}{c}\text { T 30MIN } \\
(\%)\end{array}$ \\
\hline 1 & 88,45 & 97,10 & 101,59 \\
2 & 42,01 & 88,94 & 98,650 \\
3 & 77,02 & 90,00 & 92,440 \\
4 & 85,59 & 94,89 & 97,019 \\
5 & 8,496 & 24,87 & 39,237 \\
6 & 88,12 & 103,38 & 105,83 \\
7 & 6,077 & 13,429 & 24,447 \\
8 & 20,56 & 52,218 & 95,387 \\
\hline
\end{tabular}

No gráfico 1 pode ser visualizado $\bigcirc$ perfil de dissolução comparativo dos comprimidos dos 8 lotes produzidos. 


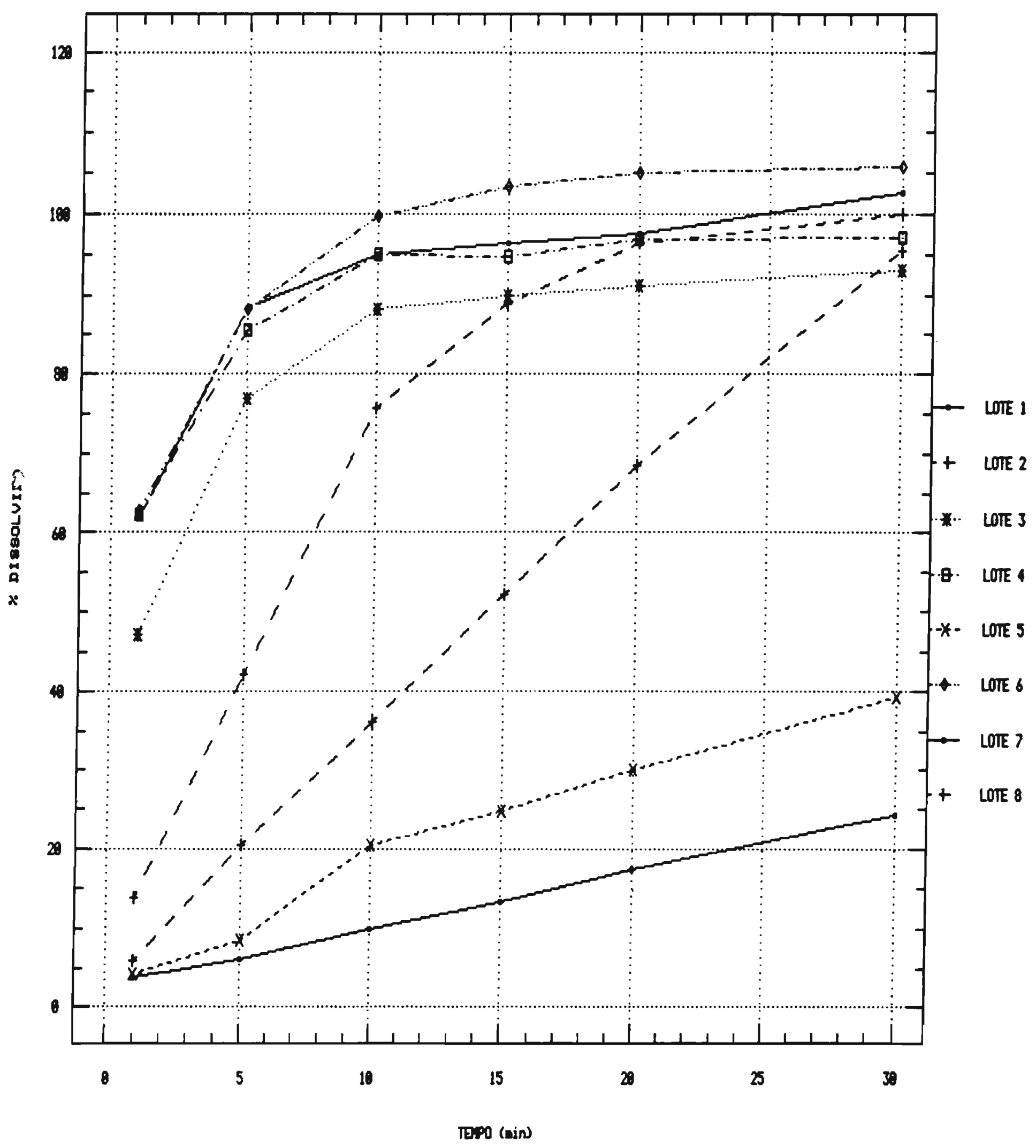

Gráfico 1 : Perfil de dissolução dos comprimidos dos 8 lotes. 
5.1.5. RELACAO ENTRE AS VARIAVEIS RESPOSTAS:

$\mathrm{Na}$ figura 6 são confrontadas, graficamente, os resultados das análises realizadas, e assim demonstradas as relações entre estas.

Nos gräficos 2, 3, 4 e 5 são apresentadas, respectivamente, as relações entre desagregação e dissolução, entre friabilidade e desagregação, friabilidade e dissolução e entre dureza e friabilidade. Os valores de desagregação foram logaritmados, em função da grande dispersão dos valores obtidos (de 0,41 a 153,50 minutos). 


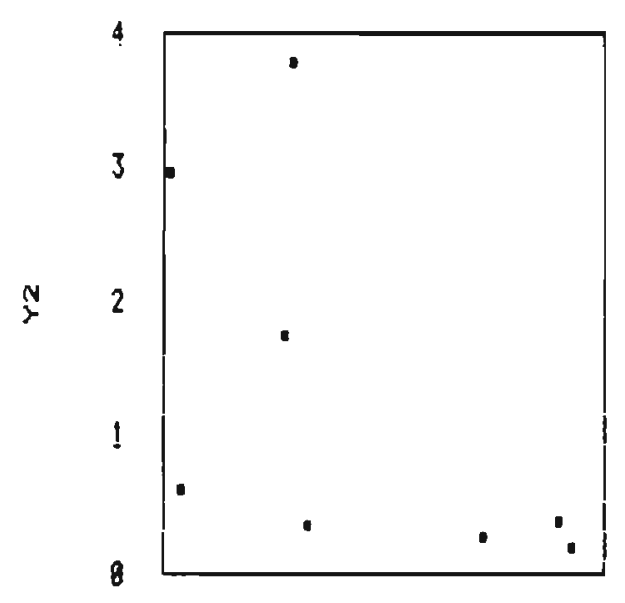

Eigura 6 : Diagramas de dispersão das variáveis respostas consideradas 2 a 2 . Y1=dureza; Y2=friabilidade; Y Y=desagregação; Y4=total dissolvido após 5 minutos
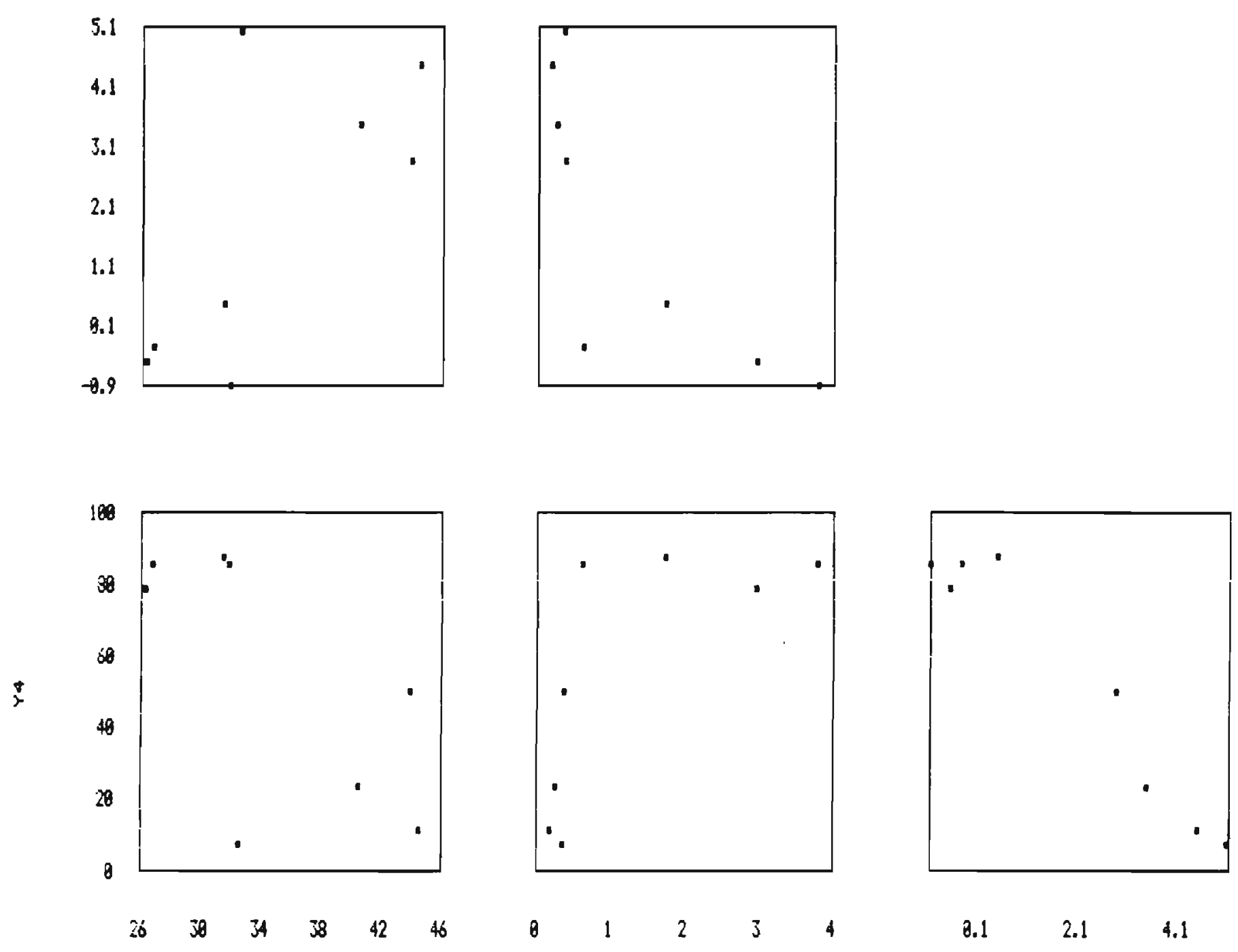

YI 42 


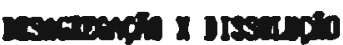

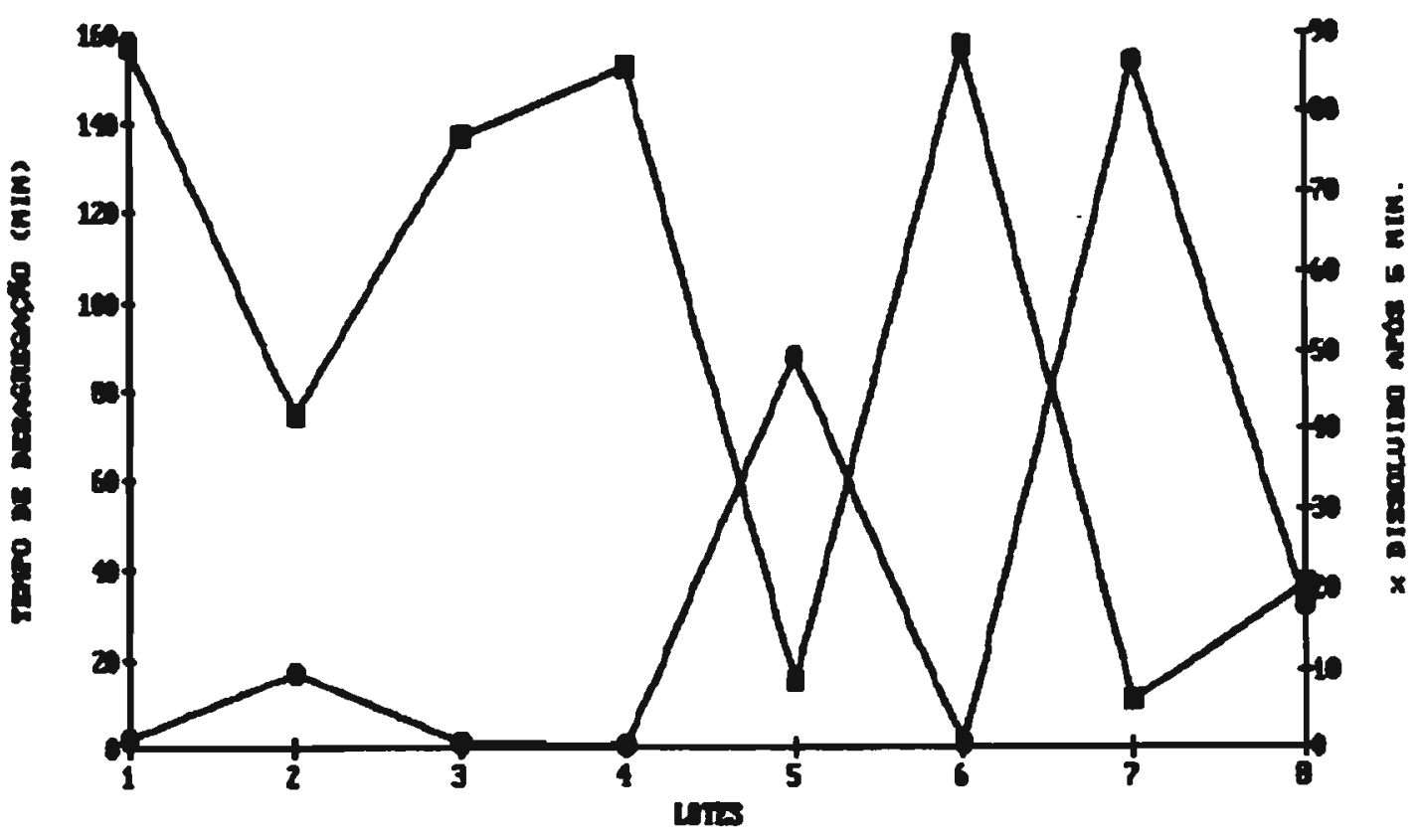

Grafico 2 : Relação desagregação X dissolução obtida nas formulações estudadas.

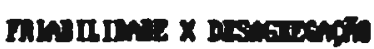

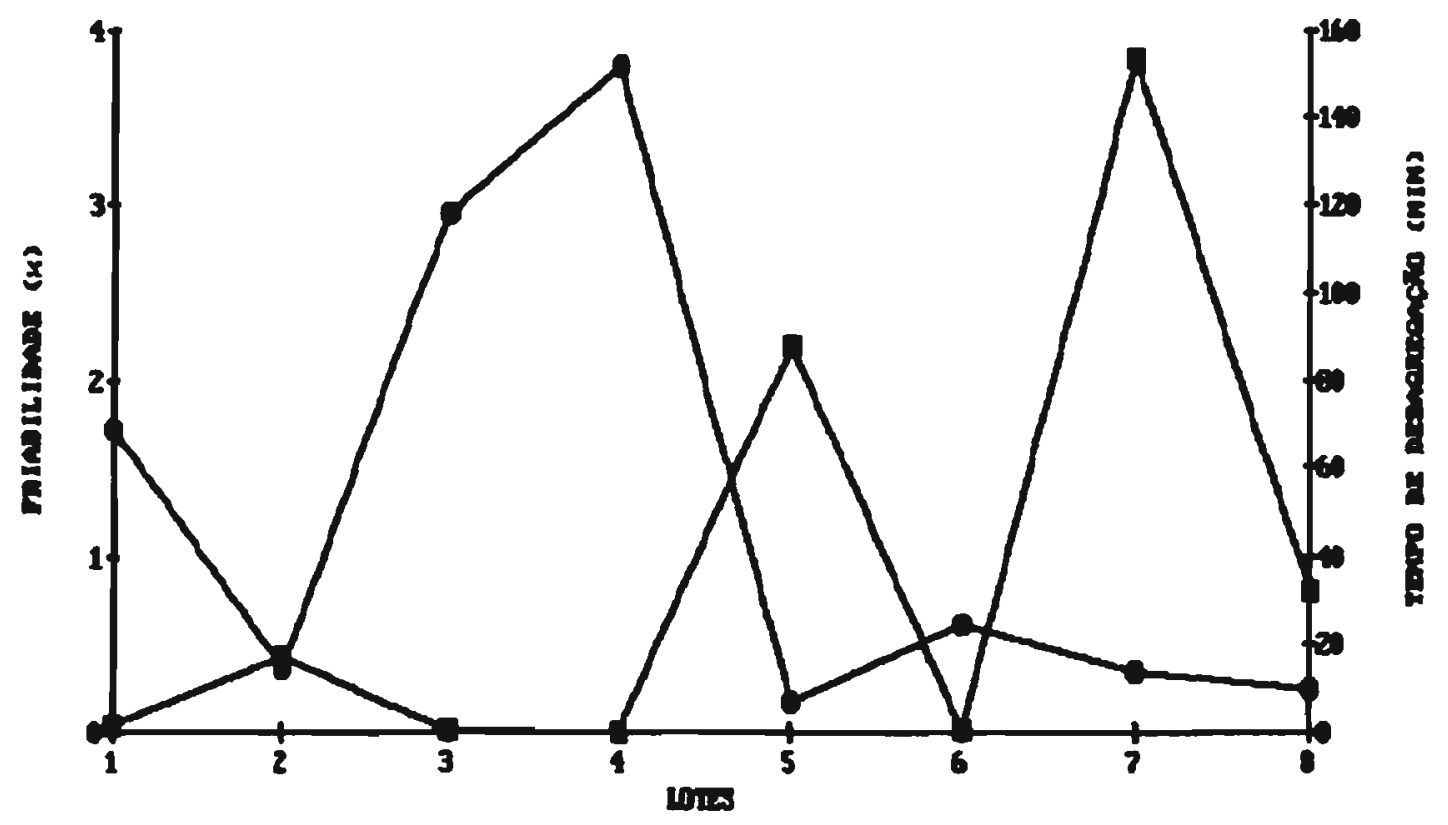

Gráfico 3 : Relaçăo friabilidade $X$ desagregaçăo obtida nas formulaçóes estudadas. 


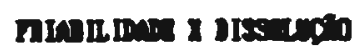

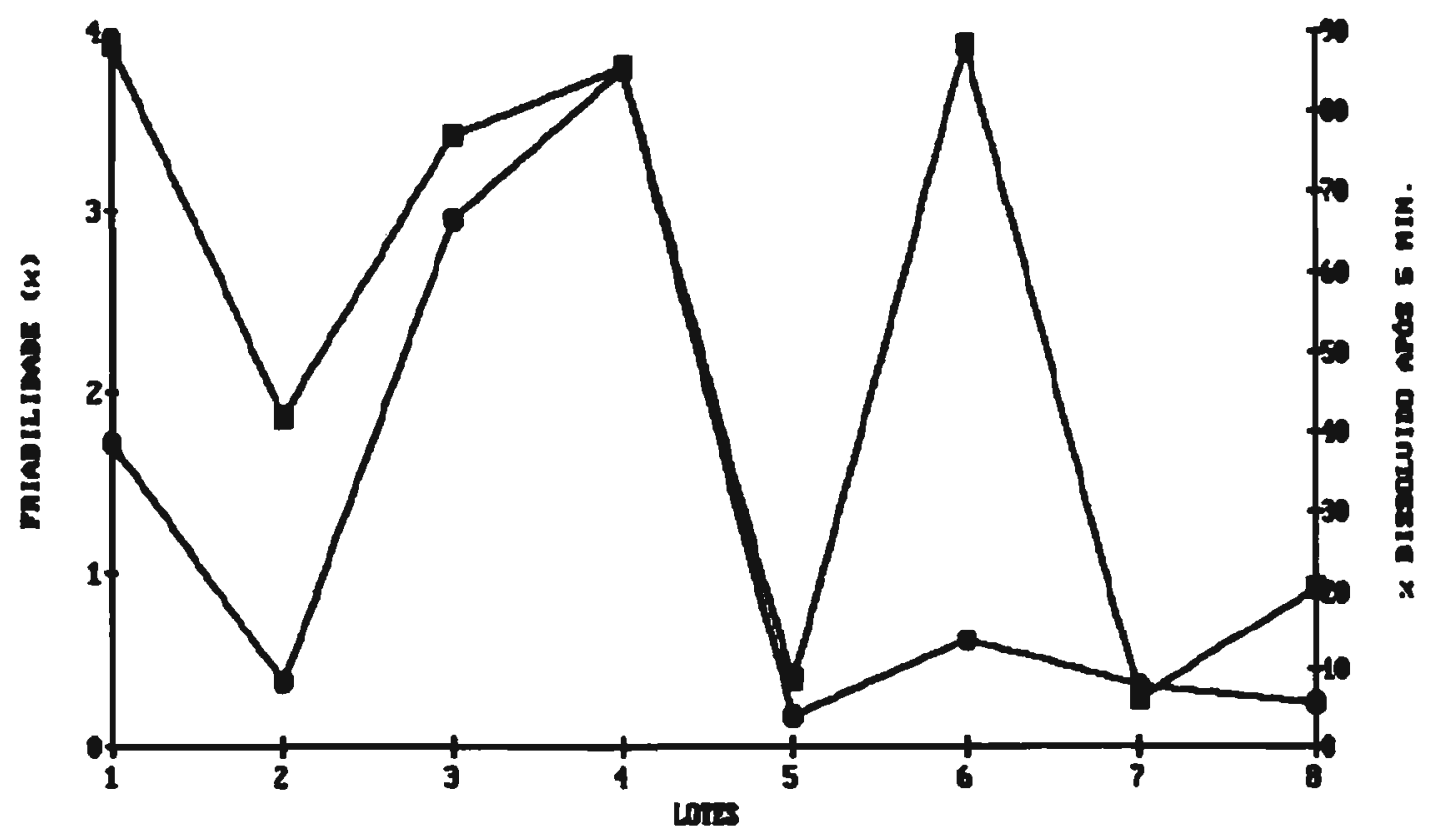

Gráfico 4 : Relação friabilidade $X$ dissolução obtida nas formulações estudadas.

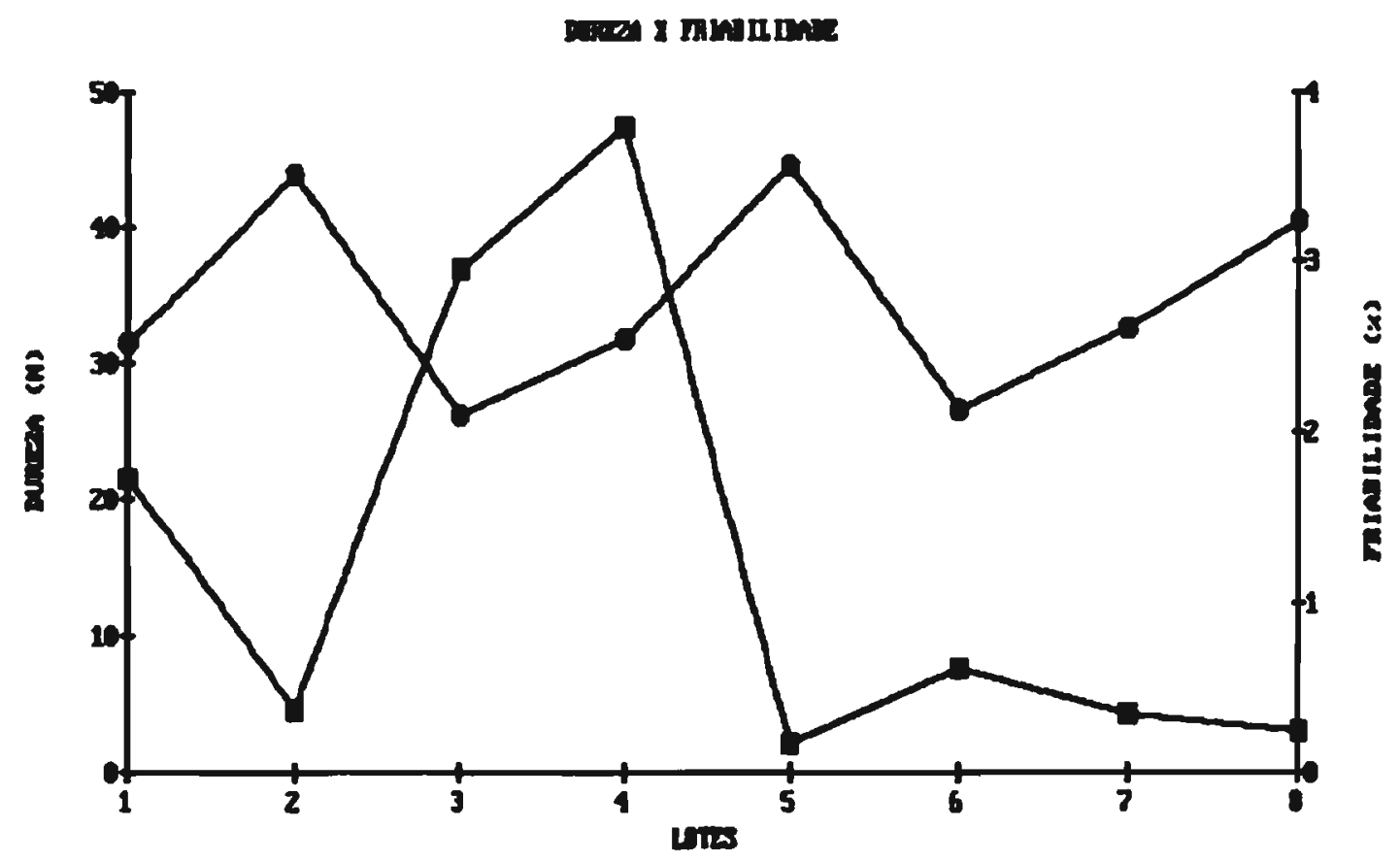

Gráfico 5 : Relação dureza X friabilidade obtida nas formulaçoses estudadas. 
5.1.6. ANALISE EXPLORATÓRIA:

$\mathrm{Na}$ figura 7, é apresentado o gràfico multivariado ideal, ou seja, o gráfico que representaria uma formulação com caracteristicas de friabilidade, dureza, desagregação e dissolução ideais. Na figura 8 são apresentados os gráficos multivariados correspondentes aos 8 lotes produzidos.

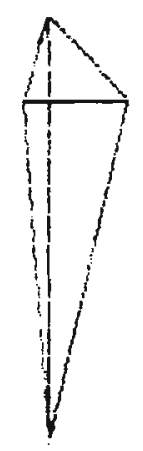

Figura 7 : Gráfico multivariado ideal (teórico) para valores de friabilidade, desagregação, total disolvido em 5 minutos $\left(T_{5 m 1 n}\right)$ e dureza. 


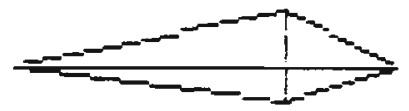

7
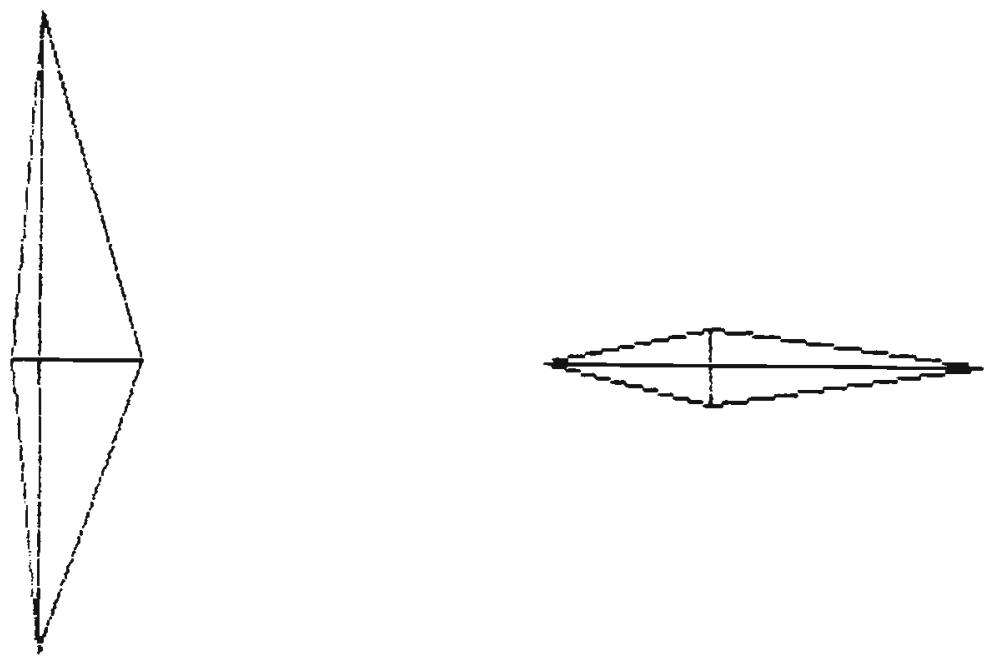

4

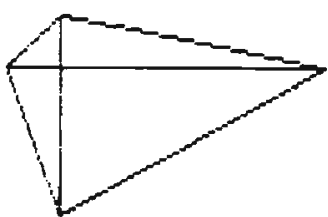

2

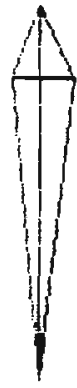

is

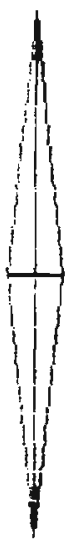

3

Figura 8 : Gráficos multivariados representativos das 8 formulações produzidas. 
5.1.7. ESTUDO DOS EEEITOS:

$\mathrm{Na}$ tabela 9 encontram-se os diversos fatores e interações entre estes fatores que, após serem submetidos à análise pelo programa STATGRAEICS, foram considerados como significativos, ou seja, realmente interferem nos resultados dos testes (respostas).

Tabela 9 : Efeitos e interações significativos obtidos pela anàlise exploratória, em programa STATGRAFICS.

\begin{tabular}{lccccccc}
\hline RESPOSTA & CONSTANTE & $x_{2}$ & $x_{2}$ & $x_{3}$ & $x_{4}$ & $x_{5}$ & $R^{*}$ \\
\hline DUREZAIY1) & 34,7125 & - & $-5,645$ & - & - & $-2,37$ & 0,9102 \\
FRIABILIDADE (Y2) & 1,27625 & 0,54625 & 0,99125 & - & 0,55625 & - & 0,9735 \\
DESAGREGACAO(Y3) & 1,93175 & - & $-2,126068$ & - & - & - & 0,9463 \\
DISSOLUCAO(Y4): & 52,0387 & - & 32,75625 & - & - & - & 0,9443 \\
\hline
\end{tabular}

IEE relaç̧o a total dissolvido ea 5 ainutos (TSein) 
PARTE II:

ENSAIO DE ESTABILIDADE FISICA DAS FORHULAC̄̃̃S 
5.2.1. ASPECTO:

5.2.1.1. COMPRIMIDOS SUBMETIDOS A TEMPERATURA AMBIENTE:

Os comprimidos mantidos à temperatura ambiente não exibiram, aparentemente, nenhuma alteração em suas caracteristicas apresentadas à superficie, após 30 e 60 dias.

5.2.1.2. COMPRIMIDOS SUBMETIDOS A TEMPERATURA DE 37 OC (ESTUFA):

Para estes comprimidos, mantidos por 30 e 60 dias em estufa à 37 oC, também não foi detectada nenhuma alteração em relação ao aspecto externo.

5.2.1.3. COMPRIMIDOS SUBMETIDOS A TEMPERATURA DE 50 OC (ESTUFA):

Os comprimidos armazenados à esta temperatura manifestaram uma acentuada alteração em suas caracteristicas. Todas as formulações, decorridos 30 ou 60 dias, apresentavam intenso odor desagradàvel.

Os comprimidos dos lotes 2,5 e 7 não resistiram à esta temperatura. Para estes comprimidos, à 30 dias já era observada na placa apenas uma massa sólida, esbranquiçada, com forte odor desagradável. Os comprimidos dos lotes 1, 4 e 8, embora tivessem resistido à 30 dias, não foram capazes de manterem sua forma 
original decorridos 60 dias, apresentando-se como uma massa solida sobre a placa, com forte odor desagradável.

Verificou-se, também, que, em maior ou menor grau, os comprimidos de todos os lotes apresentavam certa tendencia em aderirem uns aos outros e à placa de Petri na qual foram armazenados. Todos os comprimidos apresentaram, jà à 30 dias, superficie bastante irregular, porosa e com manchas esbranquiçadas.

5.2.2. PESO MEDIO, ESPESSURA, DIAMETRO, FRIABILIDADE, DUREZA E DESAGREGACAO DOS COMPRIMIDOS:

Os resultados destas análises, à 30 e 60 dias de armazenamento, além dos valores iniciais para os lotes, 1, 2, 3 , $4,5,6,7$ e 8, encontram-se, respectivamente, nas tabelas 10 , $11,12,13,14,15,16$ e 17 . 
Tabela 10 : Resultados das anàlises de peso médio (PM), espessura, diâmetro, friabilidade, dureza e tempo de desagregação dos comprimidos do lote 1 , submetidos à temperatura ambiente, 37 o $\mathrm{C}$ e 50 o $\mathrm{C}$, por 30 e 60 dias.

\begin{tabular}{|c|c|c|c|c|c|c|}
\hline DIAS & fin & $\begin{array}{c}\text { ESPESSURA } \\
\text { (a) }\end{array}$ & $\begin{array}{c}\text { DIAMETRO } \\
(\text { (na) }\end{array}$ & 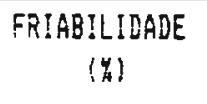 & $\begin{array}{l}\text { DUREZA } \\
\text { (N) }\end{array}$ & $\begin{array}{c}\text { DESAGREGACAO } \\
\text { (min) }\end{array}$ \\
\hline \multicolumn{7}{|c|}{ TEMPERATURA AMBIENTE } \\
\hline 0 & 3,429 & 2,756 & 11,998 & 1,72 & 31,47 & 1.6 \\
\hline 30 & 3,4933 & 2,752 & 11,969 & 0,67 & 28,51 & 4,07 \\
\hline 60 & 3,4943 & 2,712 & 11,970 & 1,16 & 29,38 & 4,66 \\
\hline \multicolumn{7}{|c|}{37 OC (ESTUFA) } \\
\hline 30 & 3,4720 & 2,593 & 11,957 & 1,50 & 25,52 & 5,24 \\
\hline 50 & 3,4634 & 2.747 & 11,975 & 1,49 & 34,69 & 5,28 \\
\hline \multicolumn{7}{|c|}{$50^{\circ} \mathrm{C}$ (ESTUFA) } \\
\hline 30 & 3,508 & 2,969 & 12,025 & 0,42 & 34,63 & 4,22 \\
\hline 60 & - & - & - & - & - & - \\
\hline
\end{tabular}


Tabela 11 : Resultados das anàlises de peso médio (PM), espessura, diâmetro, friabilidade, dureza e tempo de desagregação dos comprimidos do lote 2 , submetidos à temperatura ambiente, $37{ }^{\circ} \mathrm{C}$ e 50 ० $\mathrm{C}$, por 30 e 60 dias.

\begin{tabular}{|c|c|c|c|c|c|c|}
\hline DIAS & $\begin{array}{l}P y \\
(g)\end{array}$ & $\begin{array}{c}\text { ESPESELURA } \\
\text { (an) }\end{array}$ & $\begin{array}{l}\text { DIAMETRO } \\
\text { (a) }\end{array}$ & $\begin{array}{c}\text { FRIABILIDADE } \\
(y)\end{array}$ & $\begin{array}{l}\text { DUREZA } \\
\text { (N) }\end{array}$ & $\begin{array}{c}\text { DESAGREGACAO } \\
\text { (ain) }\end{array}$ \\
\hline \multicolumn{7}{|c|}{ TEMPERATURA AMBIENTE } \\
\hline 0 & 3,4830 & 2,806 & 11,993 & 0,37 & 43,94 & 17,37 \\
\hline 30 & 3,5714 & 2,866 & 11,950 & 0,26 & 40,97 & 14,90 \\
\hline 50 & 3,4298 & 2,834 & 11,969 & 0,26 & 41,80 & 14,25 \\
\hline \multicolumn{7}{|c|}{$37^{\circ}[$ (ESTUFA) } \\
\hline 30 & 3,4760 & 2,950 & 11,748 & 0,12 & 43,07 & 21,10 \\
\hline 60 & 3,5000 & 2,826 & 11,957 & 0,25 & 39,40 & 18,44 \\
\hline
\end{tabular}


Tabela 12 : Resultados das análises de peso médio (PM), espessura, diâmetro, friabilidade, dureza e tempo de desagregação dos comprimidos do lote 3 , submetidos à temperatura ambiente, $37{ }^{\circ} \mathrm{C}$ e $50{ }^{\circ} \mathrm{C}$, por 30 e 60 dias.

\begin{tabular}{|c|c|c|c|c|c|c|}
\hline DIAS & $\begin{array}{l}P H \\
(g)\end{array}$ & $\begin{array}{c}\text { ESPESSLLRA } \\
(\mathbf{n a t})\end{array}$ & $\begin{array}{c}\text { DIAMETRD } \\
\text { (aA) }\end{array}$ & $\begin{array}{c}\text { FRIABILIDADE } \\
\text { (y) }\end{array}$ & $\begin{array}{l}\text { DUREZA } \\
\text { (N) }\end{array}$ & $\begin{array}{c}\text { DESAGREGACAO } \\
\text { (ain) }\end{array}$ \\
\hline \multicolumn{7}{|c|}{ TEMPERATURA AKBIENTE } \\
\hline 0 & 3,5600 & 2,807 & 11,994 & 2,95 & 26,23 & 0,61 \\
\hline 30 & 3,5696 & 2,780 & 11,975 & 0,40 & 28,58 & 1,01 \\
\hline 60 & 3,5802 & 2,778 & 11,976 & 0,41 & 27,90 & 0,58 \\
\hline \multicolumn{7}{|c|}{37 of (ESTUFA) } \\
\hline 30 & 3,5820 & 2,786 & 11,081 & 0,50 & 27,53 & 0.68 \\
\hline 50 & 3.5656 & 2,785 & 11,985 & 0.36 & 27,57 & 0,75 \\
\hline \multicolumn{7}{|c|}{$50^{\circ} \mathrm{C}$ (ESTUFA) } \\
\hline 30 & 3,5500 & 2,959 & 12,149 & 0,27 & 21,11 & 0,75 \\
\hline 60 & 3,5670 & 3,142 & $12,355-$ & - & 17,70 & 1,89 \\
\hline
\end{tabular}


Tabela 13 : Resultados das anàlises de peso médio (PM), espessura, diâmetro, friabilidade, dureza e tempo de desagregação dos comprimidos do lote 4, submetidos à temperatura ambiente, $37{ }^{\circ} \mathrm{C}$ e 50 o , por 30 e 60 dias.

\begin{tabular}{|c|c|c|c|c|c|c|}
\hline UIAS & $\begin{array}{l}P M \\
(g)\end{array}$ & $\begin{array}{l}\text { ESPESSLFA } \\
\text { (no) }\end{array}$ & $\begin{array}{l}\text { DIAMETRO } \\
\text { (Aa) }\end{array}$ & $\begin{array}{l}\text { FRIABILIDADE } \\
(x)\end{array}$ & $\begin{array}{l}\text { DUREZA } \\
\text { (N) }\end{array}$ & $\begin{array}{c}\text { DESAGREGACAD } \\
\text { (ain) }\end{array}$ \\
\hline \multicolumn{7}{|c|}{ TEMPERATURA AMBIENTE } \\
\hline 0 & 3,5770 & 2,814 & 11,988 & 3,79 & 31,96 & 0,41 \\
\hline 30 & 3,5690 & 2,855 & 11,972 & 2,43 & 30,38 & 0,52 \\
\hline 60 & 3,6521 & 2,856 & 11,972 & 2,60 & 29,99 & 0,47 \\
\hline \multicolumn{7}{|c|}{37 of (ESTUFA) } \\
\hline 30 & 3,5730 & 2,861 & $11,97 !$ & 0,69 & 34,16 & 0,43 \\
\hline$\leq 0$ & 3,5608 & 2,853 & 11,985 & 2,40 & 32,74 & 0,51 \\
\hline \multicolumn{7}{|c|}{$50^{\circ} \mathrm{C}$ (ESTUFA) } \\
\hline 30 & 3,398 & 3,114 & 12,060 & 3,60 & 25,03 & 1,42 \\
\hline so & - & - & - & - & - & - \\
\hline
\end{tabular}


Tabela 14 : Resultados das anàlises de peso médio (PM), espessura, diâmetro, friabilidade, dureza e tempo de desagregaçăo dos comprimidos do lote 5 , submetidos à

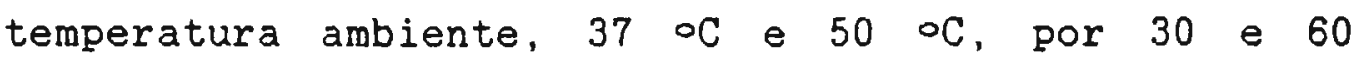
dias.

\begin{tabular}{|c|c|c|c|c|c|c|}
\hline DIAS & $\begin{array}{l}P M \\
(g)\end{array}$ & $\begin{array}{c}\text { ESPESSUFA } \\
\text { (aa) }\end{array}$ & $\begin{array}{c}\text { DIAMETRO } \\
\text { ! }\end{array}$ & $\begin{array}{c}\text { FRIABILIDADE } \\
\text { (y) }\end{array}$ & $\begin{array}{l}\text { DUREZA } \\
\text { (N) }\end{array}$ & $\begin{array}{c}\text { DESAGREGACAO } \\
\text { (nin) }\end{array}$ \\
\hline \multicolumn{7}{|c|}{ TEMPERATURA AMBIENTE } \\
\hline 0 & 3,5260 & 2,798 & 11,966 & 0,18 & 44,51 & 87,870 \\
\hline 30 & 3,5077 & 2,772 & 11,959 & 0,18 & 43,31 & 87,620 \\
\hline 60 & 3,4927 & 2,775 & 11,970 & 0,14 & 44,14 & 87,200 \\
\hline \multicolumn{7}{|c|}{37 oC (ESTUFA) } \\
\hline 30 & 3,5240 & 2,777 & 11,943 & 0,09 & 48,16 & 101,80 \\
\hline 60 & 3,5409 & 2,789 & $1:, 96 ?$ & 0,23 & 46,79 & 74,600 \\
\hline
\end{tabular}


Tabela 15 : Resultados das análises de peso médio (PM), espessura, diâmetro, friabilidade, dureza e tempo de desagregação dos comprimidos do lote 6 , submetidos à temperatura ambiente, 37 o C e 50 o , por 30 e 60 dias.

\begin{tabular}{|c|c|c|c|c|c|c|}
\hline DIAS & $\begin{array}{l}P M \\
(g)\end{array}$ & $\begin{array}{c}\text { ESPESSURA } \\
\text { (an) }\end{array}$ & $\begin{array}{c}\text { DIAMETRO } \\
\text { (a) }\end{array}$ & $\begin{array}{c}\text { FRIABILIDADE } \\
\left(\begin{array}{l}(y) \\
\text { (n) }\end{array}\right.\end{array}$ & $\begin{array}{c}\text { DUREZA } \\
\text { (N) }\end{array}$ & $\begin{array}{c}\text { DESAGREGACAO } \\
\text { (ain) }\end{array}$ \\
\hline \multicolumn{7}{|c|}{ TEMPERATURA AMBIENTE } \\
\hline 0 & 3,4620 & 2,675 & 11,960 & 0,61 & 26,71 & 0,77 \\
\hline 30 & 3,4970 & 2,717 & 11,951 & 0,36 & 23,95 & 0,84 \\
\hline so & 3,5033 & 2,720 & 11,959 & 0,28 & 26,65 & 0,86 \\
\hline \multicolumn{7}{|c|}{$37^{\circ} \mathrm{C}$ (ESTUFA) } \\
\hline 30 & 3,4330 & 2,712 & 11,954 & 0,30 & 30,58 & 1,41 \\
\hline 50 & 3,4543 & 2,717 & 11,974 & 0,31 & $21,7 \mathrm{~B}$ & 1,50 \\
\hline \multicolumn{7}{|c|}{$50^{\circ} \mathrm{C}$ (ESTUFA) } \\
\hline 30 & 3,4620 & 2,949 & 12,144 & 0,95 & 29,42 & 1,65 \\
\hline 50 & 3,4198 & 3,195 & 12,152 & 2,18 & 15,23 & 0,60 \\
\hline
\end{tabular}


Tabela 16 : Resultados das anàlises de peso médio (PM), espessura, diâmetro, friabilidade, dureza e tempo de desagregação dos comprimidos do lote 7 , submetidos à temperatura ambiente, $37^{\circ} \mathrm{C}$ e 50 o C, por 30 e 60 dias.

\begin{tabular}{|c|c|c|c|c|c|c|}
\hline DIAS & $\begin{array}{l}P Y \\
(g)\end{array}$ & $\begin{array}{c}\text { EGPESSLLRA } \\
\text { (aA) }\end{array}$ & $\begin{array}{c}\text { OIAMETRO } \\
\text { (aA) }\end{array}$ & $\begin{array}{c}\text { FRIAGILIDADE } \\
\left(\begin{array}{l}(y) \\
\text { (a) }\end{array}\right.\end{array}$ & $\begin{array}{l}\text { DUREZAA } \\
\text { (N) }\end{array}$ & $\begin{array}{c}\text { DESAGREGACAO } \\
\text { (ain) }\end{array}$ \\
\hline \multicolumn{7}{|c|}{ TEMPERATURA AMBIENTE } \\
\hline 0 & 3,5200 & 2,692 & 11,952 & 0,34 & 32,49 & 153,50 \\
\hline 30 & $3,522 !$ & 2,801 & 11,954 & 0,18 & 42,18 & 153,20 \\
\hline 60 & 3,5217 & 2,719 & 11,950 & 0,23 & 38,99 & 154,80 \\
\hline \multicolumn{7}{|c|}{37 or (ESTUFA) } \\
\hline 30 & 3,4660 & 2,753 & 11,935 & 0,18 & 39,41 & 133,50 \\
\hline 60 & 3,4717 & 2,749 & 11,972 & 0,25 & 36,85 & 135,00 \\
\hline
\end{tabular}


Tabela 17 : Resultados das anàlises de peso médio (PM), espessura, diâmetro, friabilidade, dureza e tempo de desagregação dos comprimidos do lote 8 , submetidos à temperatura ambiente, $37^{\circ} \mathrm{C}$ e $50^{\circ} \mathrm{C}$, por 30 e $60 \mathrm{dias}$.

\begin{tabular}{|c|c|c|c|c|c|c|}
\hline DIAS & $\begin{array}{l}P H \\
(g)\end{array}$ & $\begin{array}{c}\text { ESPESSIJRA } \\
\text { (u) }\end{array}$ & $\begin{array}{c}\text { DIAMETRO } \\
\text { (a) }\end{array}$ & $\begin{array}{c}\text { FRIABILIDADE } \\
\text { (l) }\end{array}$ & $\begin{array}{c}\text { DUUREIA } \\
\text { (N) }\end{array}$ & $\begin{array}{c}\text { DESAGREGACAD } \\
\text { (ain) }\end{array}$ \\
\hline \multicolumn{7}{|c|}{ TENPERATURA AMBIENTE } \\
\hline 0 & 3,5360 & 2,698 & 11,960 & 0,25 & 40,49 & 32,04 \\
\hline 30 & 3,5186 & 2,734 & 11,969 & 0,24 & 45,27 & 36,11 \\
\hline so & 3,5206 & 2,718 & 11,769 & 0,24 & 46,30 & 38,66 \\
\hline \multicolumn{7}{|c|}{$37^{\circ} \mathrm{C}$ (ESTUFA) } \\
\hline 30 & 3,5120 & 2,726 & 11,949 & 0,20 & 41,14 & 32,70 \\
\hline 60 & 3,5271 & 2,756 & 12,027 & 0,30 & $38,2 !$ & 39,25 \\
\hline \multicolumn{7}{|c|}{$50^{\circ} \mathrm{C}$ (ESTUFA) } \\
\hline 30 & 3,4900 & 2,753 & 12,04 & 0,46 & 37,55 & 44,75 \\
\hline 60 & - & - & - & - & - & - \\
\hline
\end{tabular}

Nas figuras 9, 10 e 11, são comparados, respectivamente, os ensaios de friabilidade, dureza e desagregação, realizados após 30 e 60 dias de armazenamento, à temperatura ambiente, 37 o $\mathrm{C}$ e 50 o C, nos 8 lotes produzidos. 

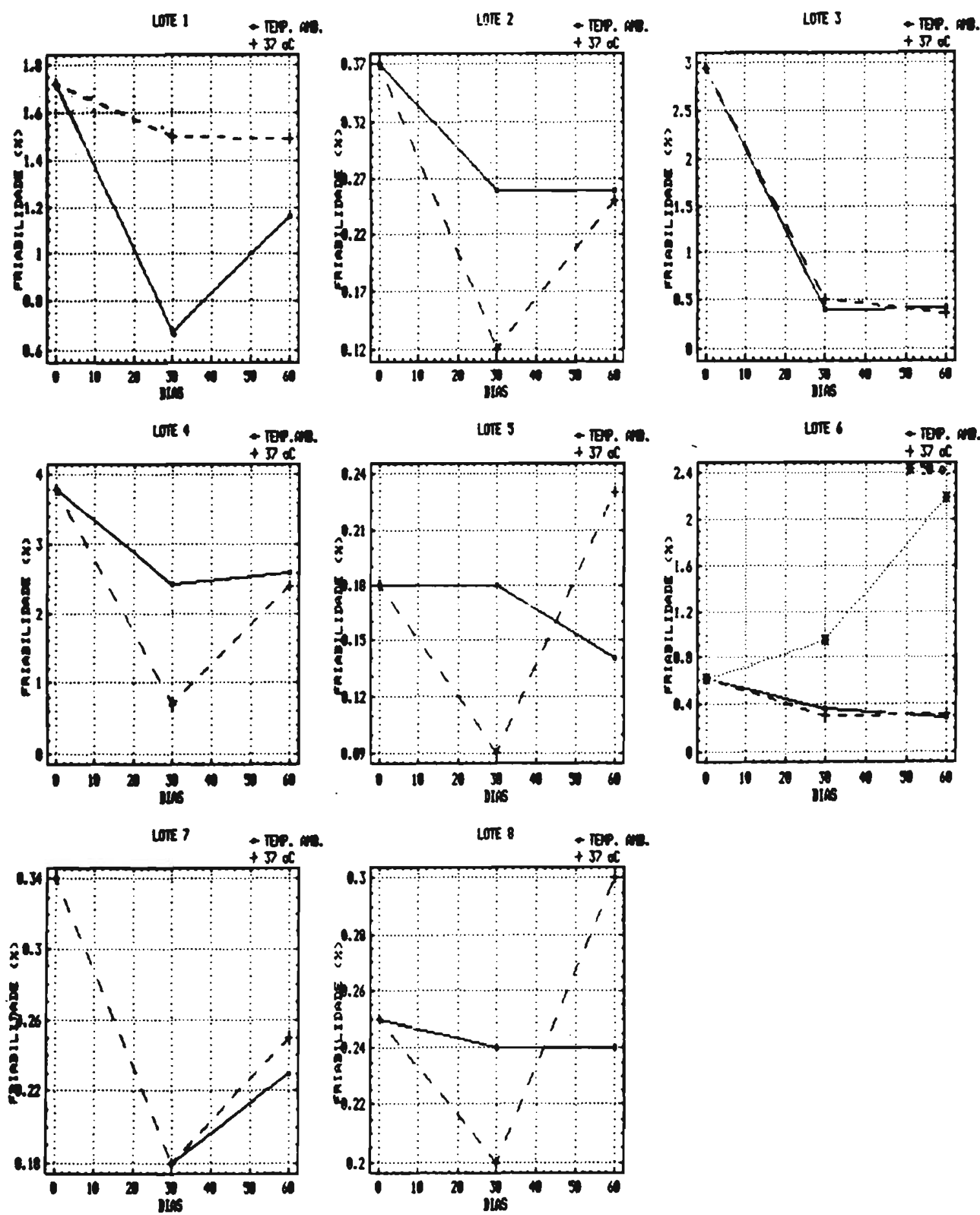

Pigura 9 : Comportamento dos diferentes lotes em relaça a friabilidade, após 30 e 60 dias à temp. ambiente, 37 ${ }^{\circ} \mathrm{C}$ e $50{ }^{\circ} \mathrm{C}$. 

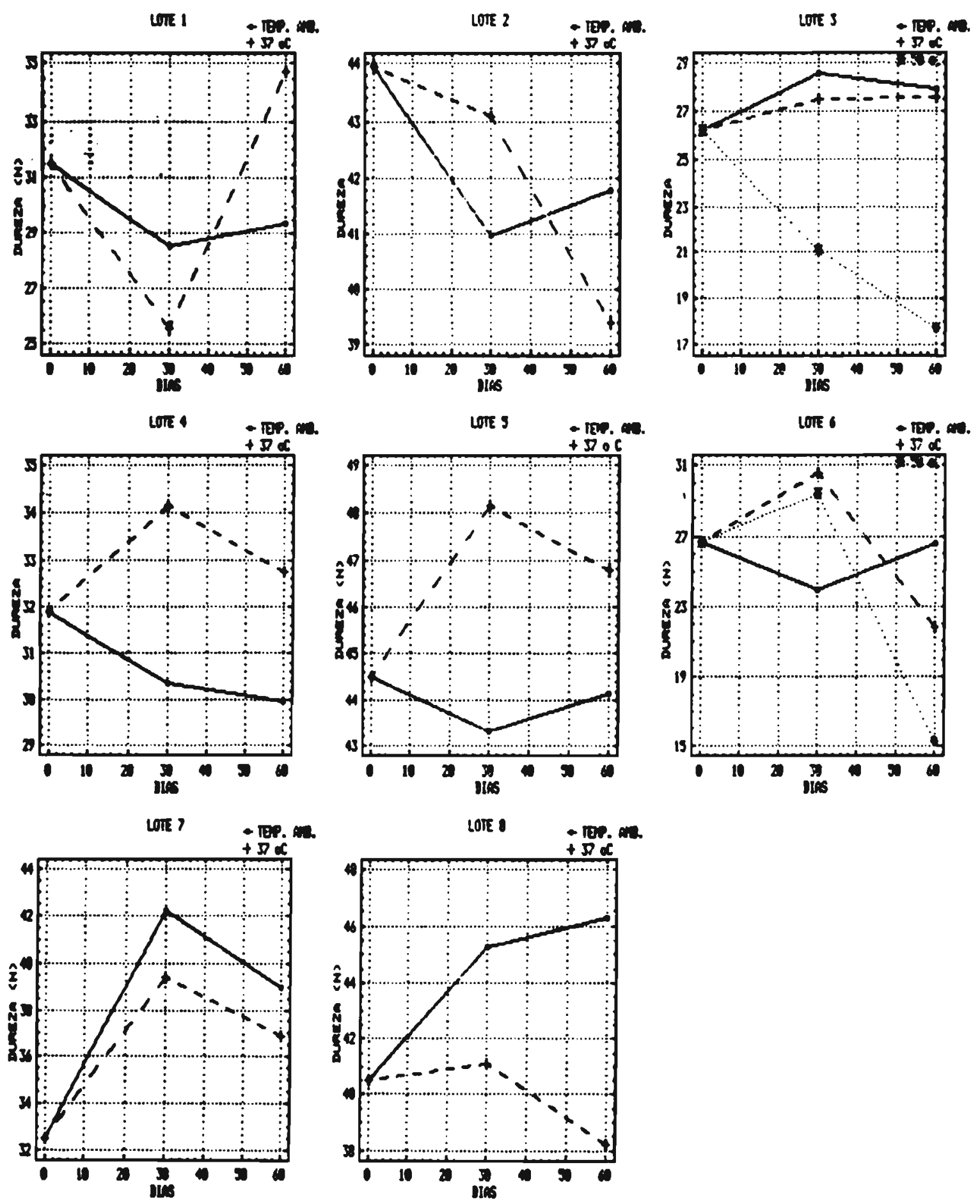

Pigura 10 : Comportamento dos diferentes lotes en relaça a dureza, após 30 e 60 dias a temp. ambiente, 37 oc e $50{ }^{\circ} \mathrm{C}$. 

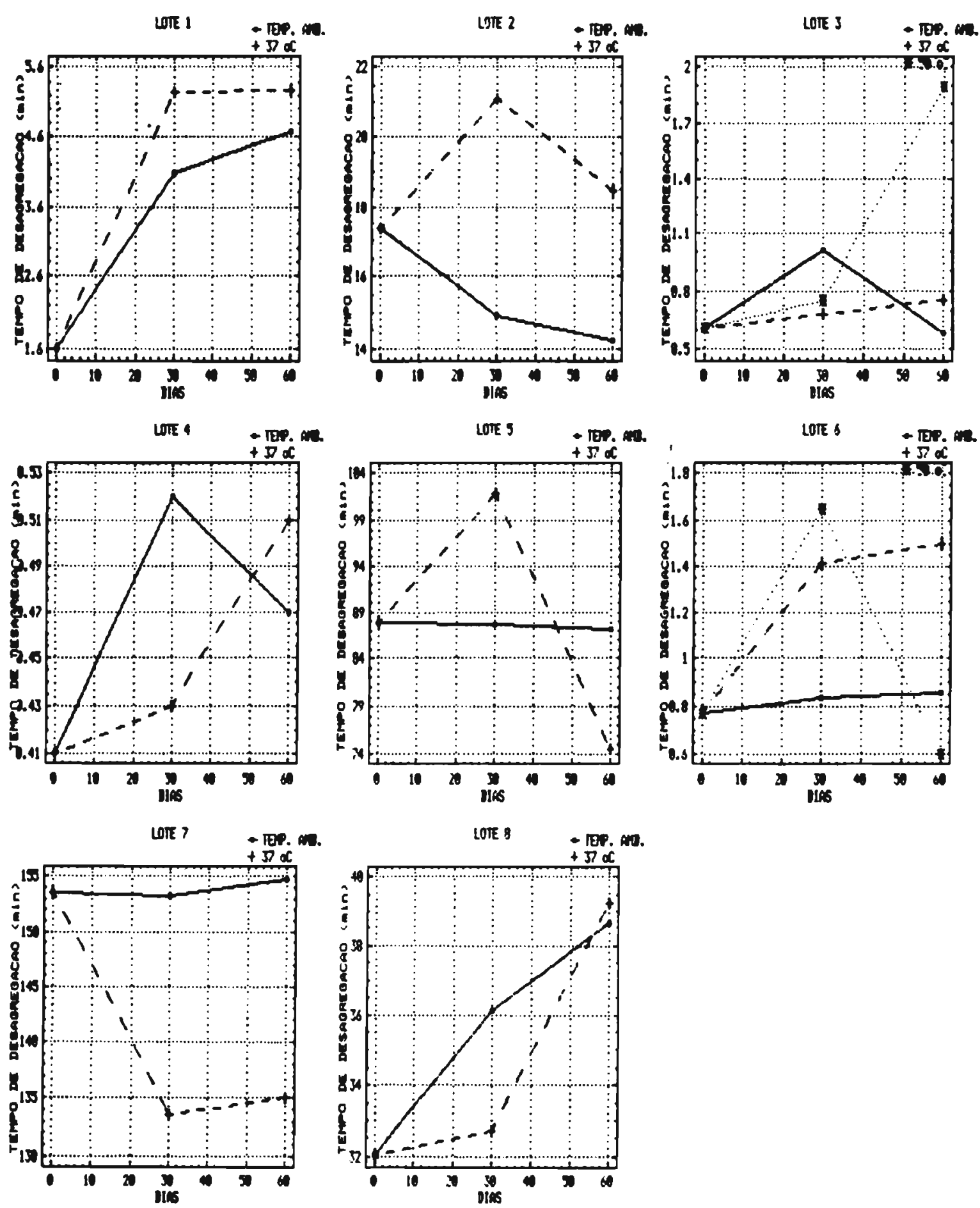

Figura 11 : Comportamento dos diferentes lotes em relaçăo ao tempo de desagregaçăo, após 30 e 60 dias à temp. ambiente, $37{ }^{\circ} \mathrm{C}$ e $50{ }^{\circ} \mathrm{C}$. 


\section{CAPITULO VI: \\ DISCUSSAO}

Os resultados obtidos são aqui analisados e comentados, fornecendo-se subsidios para as conclusões finais deste trabalho. 
o ibuprofeno, um antiinflamatório não-esteroidal, com propiedades analgésicas e antipiréticas, não é apresentado no Brasil na forma de comprimidos de $200 \mathrm{mg}$, como é corrente na Europa e EUA. Além disto, a baixa solubilidade do fármaco em meio aquoso pode ocasionar problemas de dissolução em suas formas farmacêuticas sòlidas.

o objetivo principal deste trabalho é estabelecer uma formulação de comprimidos de ibuprofeno $200 \mathrm{mg}$ que, entre outras caracteristicas, apresente um adequado perfil de dissolução.

Utilizando-se um projeto fatorial fracionado ( $1 / 4$ de $2^{5}$ ) foram obtidas e testadas 8 formulações, a partir dos seguintes excipientes: amido, goma de amido $X$ polivinilpirrolidona, mistura amido/explosol $X$ mistura amido/celulose microcristalina, talco e estearato de magnésio.

Com relação às formulações, pode-se dizer que o aparecimento de comprimidos marcados nos lotes 1,2 e 4 , inviabiliza a produção destes, considerando-se que a estética é um requisito importante em qualquer forma farmacêtica.

Todos os lotes produzidos apresentaram baixa variação de peso durante o processo de compressão, e os desvios padrões obtidos foram, para todas as formulações, muito baixos (tabela $5)$. 
Os resultados obtidos para diâmetro e espessura também não registraram grandes variações (tabela 6). Estes resultados são previsiveis, principalmente em relação ao diâmetro dos comprimidos, visto que este é determinado pela matriz utilizada durante a compressão.

No ensaio de friabilidade, os lotes 1,3 e 4 apresentaram valores elevados, respectivamente $1,72,2,95$ e 3,79 (tabela 6). Estes resultados indicam que estas formulações devem ser descartadas.

Com relação à desagregação e dissolução dos comprimidos, foram registrados valores bastante definidos para cada formulaçăo, tendo estas, individualmente, apresentado valores totalmente diferentes entre si (tabela 7). Assim, o menor tempo de desagregação obtido foi para o lote $4(0,41$ minutos $)$, e - valor mais elevado, para o lote 7 (153,5 minutos). No ensaio de dissolução, considerando-se o total dissolvido em 5 minutos $\left(T_{5 m 1 n}\right)$, o maior valor foi atingido pelos lotes 1 e 6 , ambos com $88,12 \%$ dissolvidos e o menor valor, para o lote 7 , com apenas $6,07 \%$ dissolvidos.

Examinando-se a tabela 8, onde são comparados os totais dissolvidos após 5 minutos $\left(\mathrm{T}_{5 \mathrm{~m} 1 \mathrm{n}}\right), 15$ minutos $\left(\mathrm{T}_{15 \mathrm{~m} 1 \mathrm{n}}\right)$ e após 30 minutos (T30m1n), é possivel avaliar mais detalhadamente o perfil de dissolução das formulações. Observa-se o seguinte: à 30 minutos, com exceção dos lotes 5 e 7 , todos os demais 
apresentaram um elevado percentual de dissolução, muito semelhante aos valores obtidos aos 15 minutos. Porém, estes diferem bastante dos valores obtidos à 5 minutos, principalmente para os lotes 2 e 8 . Então, avaliando-se apenas o total dissolvido em 30 minutos, pode-se dizer que, excetuando-se os lotes 5 e 7, todos os outros lotes seriam razoavelmente semelhantes. De fato, observando-se o grafico 1 , onde são mostrados os perfis de dissolução de todas as formulações, evidencia-se que o comportamento destas, em relação à dissolução é bastante diferente, e que o lote 6 é o que apresenta o perfil mais adequado, em comparação às outras formulações.

A relação entre as variáveis respostas, demonstradas pela figura 6, estabeleceu analogia entre os seguintes ensaios:

- DESAGREGACAO E DISSOLUÇO ( $Y 3$ e $Y 4)$ : Quanto menor a desagregação, maior o total dissolvido em 5 minutos (gràfico 2).

- FRIABILIDADE E DESAGREGACAO ( $Y 2$ E Y3): Quanto menor a friabilidade, maior o tempo de desagregação dos comprimidos (gräfico 3)

- ERIABILIDADE E DISSOLUCAO ( $\mathrm{Y}$ e $\mathrm{Y} 4$ ): Quanto maior a friabilidade, até um certo valor (aproximadamente 1), maior o total dissolvido do fármaco em 5 minutos. Valores mais elevados de friabilidade não causaram interferência significativa no ensaio de dissolução (gräfico 4). 
- DUREZA E FRIABILIDADE ( $Y 1$ e $Y 2$ ): A friabilidade apresentou valores mais elevados para valores de dureza até aproximadamente 30. Acima deste valor, a friabilidade apresentou queda brusca, atingindo-se um patamar em niveis baixos (gráfico 5 ).

$\mathrm{Na}$ explicação da causa destas relações, não se pode deixar de considerar aspectos relativos à formulaçăo. Na relação friabilidade $X$ desagregação e friabilidade $X$ dissolução, nota-se que valores maiores de friabilidade favoreceram a desagregação e a dissolução dos comprimidos. Porém, estes valores menores de friabilidade estiveram relacionados com o uso da goma de amido como aglutinante. A mesma analogia pode ser estendida à relação dureza $\mathrm{X}$ friabilidade.

A relação desagregação X dissolução é óbvia. A figura 1 ilustra claramente esta relação. Se o comprimido desagrega-se mais rapidamente, a dissolução evidentemente serà maior.

A anàlise exploratória das formulações produzidas (figuras 7 e 8), indica que as formulações 1 e 6 são as mais adequadas do ponto de vista dos parâmetros evidenciados no gràfico multivariado. Porém, em relaçăo à formulação 1 , devem ser considerados os seguintes aspectos: (1) a friabilidade apresentada pela formulação - 1,72\% - Isto ocasionou um ligeiro deslocamento do eixo superior no gráfico multivariado, que corresponde aos valores de friabilidade. (2) a formulação 
apresentou problemas relativos ao seu aspecto, com o surgimento de comprimidos marcados.

0 estudo dos efeitos, obtido a partir do programa STATGRAFICS, possibilitou que se estabelecesse quais os fatores que influenciaram cada variável resposta (tabela 9). E possivel, a partir dos dados fornecidos, obter equações que descrevem os efeitos de cada fator, nas diversas formulações. Tem-se então:

. DURE2A: $\quad \gamma_{1}=34,7125-5,645\left(X_{2}\right)-2,37\left(X_{5}\right)$

- FRIABILIDADE: $Y_{2}=1,27625+0,54625\left(X_{1}\right)+0,99125\left(X_{2}\right)+0,55625\left(X_{4}\right)$

- DESAGREGACAO: $Y_{3}=1,83175-2,126068\left(X_{2}\right)$

. DISSOLUCAO: $Y_{4}=52,0387+32,75625\left(X_{2}\right)$

Estas equações, então, podem ser interpretadas da seguinte maneira, utilizando-se a dureza $\left(Y_{1}\right)$ como exemplo: esta variàvel-resposta (dureza) é influenciada pelos fatores $\mathrm{X}_{2}$ (aglutinante) e $X_{5}$ (estearato de magnésio). Os sinais negativos significam que quanto menor o fator, maior serà a resposta, ou seja, no caso do fator $\mathrm{X}_{2}$, quando utilizou-se o nivel "-" (polivinilpirrolidona), obteve-se valores mais elevados de dureza e para o fator $X_{5}$, um nivel "-" (3 mg) proporcionou, também, valores mais elevados de dureza.

Estendendo-se a interpretação aos outros fatores, verificou-se que a friabilidade $\left(Y_{2}\right)$ foi influenciada pela quantidade de amido $\left(X_{1}\right)$, pelo aglutinante utilizado $\left(X_{2}\right)$ e pela 
quantidade de talco $\left(X_{4}\right)$ presentes na formulação. Quando utilizou-se o nivel "+" de amido (35 mg), a friabilidade foi maior. No caso do aglutinante, o nivel "+" (goma de amido) proporcionou valores de friabilidade mais elevados, e, para o talco, o nivel "+" (7 mg) também proporcionou valores mais elevados neste ensaio. A desagregação (Y3) sofreu influência da quantidade de amido $\left(X_{1}\right)$ presente na formulação, sendo que um nivel "-" de amido proporcionou valores mais elevados do tempo de desagregação.

O ensaio de dissolução, expresso em relação ao total dissolvido após 5 minutos $(\operatorname{Tsm} 1 \mathrm{n})$, foi influenciado pelo tipo de aglutinante utilizado. O nivel "+" (goma de amido), proporcionou valores mais elevados de T5min.

Durante a avaliação da estabilidade fisica das formulações, foram verificadas as transformações ocorridas nestas, e a simples observação do aspecto externo dos comprimidos, por si só é bastante interessante. Nota-se que os comprimidos mantidos à temperatura ambiente e à 37 o C não sofreram transformações aparentes.

Porém, à 50 oC, as transformações ocorridas foram, com relaçăo ao aspecto, bastante visiveis. Os comprimidos dos lotes 2, 5 e 7 não resistiram à esta temperatura, e os comprimidos dos lotes 1,4 e 8 resistiram apenas à 30 dias, e não à 60 dias. 
Apenas alguns dos comprimidos do lote 3 resistiram à esta temperatura, por 60 dias, porém, em número insuficiente para a realização de todas as anàlises. O lote 6 foi o único em que os comprimidos resistiram à esta temperatura, durante 30 e 60 dias, porém com aspecto também bastante alterado.

HELMAN \& DALESIO (1971), em relação à este tipo de comportamento de comprimidos submetidos ao teste de envelhecimento, citam: "Durante o periodo de envelhecimento, o aspecto dos comprimidos pode permanecer sem alterações, à uma dada temperatura, por exemplo $40^{\circ} \mathrm{C}$, e se tornarem inaceitáveis à 50 oC, por apresentarem manchas, diminuição da dureza, etc. Isto não significa que se deve deixar de lado a fórmula ou o procedimento de elaboração, pois não necessariamente o que ocorre à 50 oC deve ocorrer à 40 oC; às vezes pode ocorrer a fusão de um ou mais integrantes da formulação e esta ser a causa da diminuição da dureza. Existem comprimidos que se rompem ou aumentam de tamanho à temperaturas elevadas porém, permanecem sem mudanças à temperatura ambiente."

Portanto, esta grande diferença no comportamento das formulações não implica na sua inutilização. A temperatura de 50 oC parece, então, năo ser adequada para o ensaio de envelhecimento de comprimidos de ibuprofeno. Porém, uma observação importante pode ser feita: os lotes que não resistiram à esta temperatura (lotes 2,5 e 7) foram granulados com polivinilpirrolidona. Considerando-se, também, que os comprimidos 
produzidos com este polimero foram aqueles nos quais o tempo de desagregação apresentaram valores mais elevados, é possivel suscitar a hipotese de que pode haver algum tipo de interação do ibuprofeno com este excipiente, pelo menos nas condições aqui utilizadas. Os trabalhos de HIGUCHI et alii (1954a, 1954b), relatando várias interações de polivinilpirrolidona com outros fármacos, reforça esta hipótese.

No entanto, NESIC et alii (1990), num estudo de sistemas polivinilpirrolidona-ibuprofeno, relata que o polimero é capaz de diminuir o tempo de desagregação do ibuprofeno quando adicionado diretamente sobre o fármaco, além de melhorar a dureza dos comprimidos.

Então, esta interação aqui encontrada merece ser melhor estudada e elucidada, o que servira de base para planos futuros.

As transformações fisicas anotadas para a friabilidade (figura 9), dureza (figura 10) e desagregação (figura 11) dos comprimidos, durante $\circ$ ensaio de envelhecimento, não parecem indicar transformações muito profundas.

No ensaio de friabilidade, a tendência registrada foi da aproximação dos valores, à 60 dias, e de maneira também genérica, os valores estiveram abaixo do valor inicial (figura $9)$. 
Para a dureza, em quase todas as análises, observa-se uma tendência da inversão do comportamento dos comprimidos de 30 para 60 dias. Ou seja, até 30 dias, se o comportamento dos comprimidos era uma tendência à valores mais elevados de dureza, à 60 dias havia uma tendência de queda destes valores (figura 10)

Em relação ao tempo de desagregação, observa-se que, na maioria dos casos, houve uma tendência, após o armazenamento, de elevação dos valores inicialmente encontrados (figura 11).

Para a grande maioria dos casos, as relações friabilidade $X$ desagregação e friabilidade $X$ dureza foram respeitadas após o armazenamento. 


\section{CAPITULO VII :}

\section{CONCLUS OES}

Neste capitulo final são apresentadas, sob a forma de tópicos, as conclusões essenciais a partir dos resultados aqui obtidos. 
As principais conclusões oriundas deste trabalho podem ser assim enumeradas:

1. Dentre as formulações testadas, a correspondente ao lote 6 parece ter sido a mais adequada, considerando-se os aspectos aqui estudados. Esta formulação é constituida por: ibuprofeno - 200; amido - 47; lactose - 72; celulose microcristalina 23 ; estearato de magnésio - 8 .

2. A formulação correspondente ao lote 6 , em relação ao ensaio de dissolução aqui executado, mostrou-se apropriada. A formulação em questão não apenas apresentou o melhor perfil de dissolução, como também, o ensaio de desagregação demonstrou ser esta, capaz de liberar muito rapidamente o principio ativo nela contido.

3. Com o auxilio do programa STATGRAEICS, foi possivel estabelecer quais fatores influenciaram os diversos parâmetros estudados. A dureza apresentou valores mais elevados com o uso da polivinilpirrolidona (aglutinante) e com quantidade mais elevada de estearato de magnésio. A friabilidade dos comprimidos foi maior com quantidades mais elevadas do diluente (amido), na presença de talco e com o uso da goma de amido como aglutinante. O tempo de desagregação e a dissolução dos comprimidos foram influenciados pelo tipo de aglutinante utilizado, sendo obtidos resultados mais satisfatòrios nestes ensaios com o uso da goma de amido. 
4. Foram estabelecidas, para as formulaçðes estudadas, similitudes entre a desagregação e a dissolução, friabilidade e desagregação, friabilidade e dissolução e entre a dureza e a friabilidade dos comprimidos.

5. No ensaio de estabilidade fisica das formulações, evidenciouse que estas não sofrem transformações radicais à temperatura ambiente e à $37^{\circ} \mathrm{C}$, durante um periodo de 60 dias.

6. O armazenamento à 50 oC dos comprimidos das oito formulações produzidas, mostrou-se inadequado para o estudo das transformações fisicas decorrentes da ação do envelhecimento sobre estas. Porém, constatou-se que, nas formulações em que a polivinilpirrolidona foi utilizada como aglutinante, ocorreram as transformações mais significativas.

7. O comportamento, à 50 oC, das formulações nas quais foi utilizada a polivinilpirrolidona como aglutinante e o fato de que estas mesmas formulações apresentaram tempos mais elevados de desagregação, parecem indicar uma interação entre este excipiente e o ibuprofeno, pelo menos nos sistemas estudados. Esta aparente interação, que se mostrou indesejàvel, deverà ser objeto de investigações futuras. 


\section{REEERENCIAS BIBLIOGRAEICAS}

São ordenadas, em ordem alfabética, as publicações citadas neste trabalho, estando estas de acordo com a norma NBR 6023/89 preconizada pela Associacão Brasileira de Normas Técnicas (ABNT). As abreviaturas dos titulos dos periodicos estão de acordo com o CHEMICAL ABSTRACTS SERVICE SOURCE INDEX (CASSI), 1990. 
01. ADAMS, S.S., CLIFEE, E.E. LESSEL, B. , NICHOLSON, J.S. Some biological properties of 2-(4-isobutylphenyl)propionic acid. J. Pharm.Sci, Washington, v.56, n.12, p.1686, 1967 .

02. ADAMS, S.S., CLIFEE, E.E., LESSEL, B., NICHOLSON, J.S. Some biological properties of ibufenac, a new antirheumatic drug. Nature, London, v.200, n. 4903, p.271-273, 1963.

03. ADAMS, S.S. Ibuprofen: alcume caratteristiche di laboratorio. Minerva Med., Turin, v.64, p.2395, 1973.

04. ALAM, A.S., PARROT, E.L. Effect of aging on some physical properties of hydrochlorothiazide tablets. J. Pharm. Sci.,Washington, v.60, n.2, p.263-266, 1971.

05. ALTMAN, R.D. Review of ibuprofen for osteoarthritis. Am. $J$. Med., New York, v.77, n.1A, p.10-18, 1984.

06. AULTON, M.E. , TRAVERS, D.N. , WHITE, P.J.P. Strain recovery of compacts on extended storage. J. Pharm. Pharmacol., London, v.25, suppl., p.79P-86P, 1973.

07. BANKER, G. , ANDERSON, N.R. Tablets. In: LACHMAN, L., LIEBERMAN, H.A. , KANIG, J.L., eds. The theory and practice of industrial pharmacy. Philadelphia: Lea \& Febiger, 1986. p. 29.3-345.

08. BANKER, G.S., PECK, G.E. BALEY, G. Tablet formulation and design. In: LIEBERMAN, H.A. , LACHMAN, L. eds. Bharmaceutical dosage forms: tablets. New York: Marcel Dekker, 1980. v.1, p.72-86.

09. BARRY, B.W. Transdermal drug delivery. In: JOHNSON, P. LLOYD-JONES, J.G. , eds. Drug delivery systems: fundamentals and techniques. Chichester: Ellis Horwood, 1987 . P. 200-223.

10. BENNETT, C.A. , ERANKLIN, N.L. Statistical analysis in chemistry and the chemical industry. New York: John Wiley, 1954. P. 493-515. 
11. BOLTON, S. Pharmaceutical statistics: practical and clinical applications. New York: Marcel Dekker, 1984. p.421-452, 258-279.

12. BOLTON, S. Factorial designs in pharmaceutical stability studies. J. Pharm. Sci., Washington, v.72, n.1, p.362-366, 1983 .

13. BONNEY, S.L. , NORTHINGTON, R.S., HEDRICH, D.A., WALKER, B.R. Renal safety of two analgesics used over the counter: ibuprofen and aspirin. Clin. Pharmacol. Ther, St. Louis, v. 40, n.4, p. 373-377, 1986 .

14. BRAMANTI, G. MAZZI, G., MURA, P. PINZAUTI, S., LA PORTA, E. ' PAPINI, $\mathrm{P}$. Studio IN VITRO sulla velocità di assorbimento intestinale di farmaci poco solubili con diversa granulometria. Boll. Chim. Earm. Milan, v.119, p. 267-274, 1980 .

15. BRITISH pharmacopoeia 1988. London: Her Majesty's Stationery Office, 1988. p.307.

16. BROOKS, C.D., SCHLAGEL, C.A., SEKHAR, N.C., SOBOTA, J.T. Tolerance and pharmacology of ibuprofen. Curr. Ther. Res. Tenafly, v.15, p.180-190,1973.

17. BUSSON, M. Update on ibuprofen: review article. I. Int. Med. Res,, Northampton, v.14, p.53-62, 1986.

18. CARCAMO, E. C. Cinética de disolucion de medicamentos. Washington: Secretaria General de la Organización de los Estados Americanos, 1981. 102 p.

19. CESCHEL, G.C., DUNCAN, S., DALL OLIO, G., LUPO, C. , GIANI, C. Valutazione "in vitro" della biodisponibilità nelle formulazioni solide per os. Boll. Chim. Farm., Milano. v.112, p.645-664, 1973 .

20. CHIARINI, A. TARTARINI, A. , EINI, A. pH-solubility relationship and partition coeficients for some antiinflammatory arylaliphatic acids. Arch. Bharm., Weinheim, v.317, n.84, p.268-273, 1984 . 
21. CHOW, D.D. , KARARA, A.H. Characterization, dissolution and bioavailability in rats of ibuprofen - B-cyclodextrin complex system. Int. J. Pharm., Amsterdam, v.28, n.2-3, p. $95-101,1986$.

22. CID, E. , JAMINET, F. Influence des adjuvants sur la vitesse de dissolution et la stabilité de l'acide acétylsalicylique dans les comprimés. I. Effets de quelques agents disintégrants. J. Pharm. Belg., v.26, n.1, p.38-48. 1971.

23. CLARKE'S isolation and identification of drugs. 2.ed. London: Pharmaceutical Press, 1986. p.677.

24. COCHRAN, W.G. , COX, G.M. Experimental designs, 2 ed. New York: John Wiley, 1957. p.244-276.

25. COOPER, B.F., BRECHT, E.A. Surfactants in tablets to improve desintegration. J Am. Pharm. Assoc. Sci. Ed, Washington, v.46, n.9, p.520-524, 1957.

26. COOPER, S.A. Five studies on ibuprofen for postsurgical dental pain. Am. J. Med. New York, v.77, n.1A, p.70-77, 1984 .

27. CORSON, S.L. , BOLOGNESE, R.J. Ibuprofen therapy for dysmenorrhea. I. Reprod. Med., Chicago, v.20, n.5, p.246252,1978 .

28. DAVIS, S.S. Scientific principles in design of drug dosage formulations. Br. Med. J., London, v.1, p.102- 106, 1972.

29. DASH, B.H. , BLANK, R.G., SCHACHTEL, B.P., SMITH, A.J. Ibuprofen tablets: dissolution versus bioavailability. Drug Dev. Ind. Pharm., New York, v.11, p.1629-1645, 1988. Apud: Int. Pharm. Abstr, Bethesda, v.26, n.13, abstr. n. 2607688,1989 .

30. DAWOOD, M.Y. Ibuprofen and dysmenorrhea. Am. J.Med., New York, v.77, n.1A, p.87-94, 1984.

31. DICIONARIO de especialidades farmacêuticas (DEF). 19.ed. Rio de Janeiro: Publicações Médicas, 1990/1991. 583 p. 
32. DIONNE, R.A. , CAMPBELL, R.A. COOPER, S.A., HALL, D.L., BUCKINGHAM , B. Suppression of postoperative pain by preoperative administration of ibuprofen in comparisom to placebo, acetaminophen, and acetaminophen plus codeine. I. Clin. Pharmacol, v.23, p.37-43, 1983.

33. DONDONI, A., DALL OCCO, T. , FANTIN, G., MEDICI, A. PEDRINI, $P$. , ROSSETTI, $V$. Studies on the actual and potential impurities in ibuprofen. Earmaco Ed. Prat. Pavia, v.41, n.7, p.237-244, 1986.

34. DRUG evaluations annual 1991. Milwaukee: American Medical Association. 1991. p.112.

35. DRUGDEX (R) system - drug evaluation monographs. In: MICROMEDEX CCIS - Computerized Clinical Information System (R), v.73, 1992. [CD-Rom].

36. DUCKWORTH, W. E. Statistical techniques in technological research: an aid to research productivity. London: Methuen, 1968. P.60-87, 96-112.

37. FARMACOPEIA brasileira 4. ed. São Paulo: Atheneu, 1988. pt 1.

38. ERTEL, K.D. HEASLEY, R.A. , KOEGEL, C. , CHAKRABARTI, A., CAESTENSEN, J.T. Determination of ibuprofen vapor pressure at temperatures of pharmaceutical interest. $J$. Pharm. Sci, Washington, v.79, n.6, p.552, 1990.

39. FINI, A., ZECCHI, V., RODRIGUEZ, L., TARTARINI, A. Solubility-dissolution relationship for ibuprofen, fenbufen and their sodium salts in acid medium. Bharm. Acta Helv., Bern, v.59, n.4, p.106-108, 1984.

40. FINI, A. , ZECCHI, V., TARTARINI, A. Dissolution profiles of NSAID carboxylic acids and their salts with different counter ions. Bharm. Acta Helv., Bern, v.60, n.2, p.58-62, 1985 .

41. FLORENCE, A.T. HALBERT, G.W. Formulation. In: HANSCH, C. SAMMES, P.G. TAYLOR, J.B., eds. Comprehensive medicinal chemistry. The rational designs, mechanistic study \& therapeutic application of chemical compounds. Oxford: Pergamon Press, 1990. v.5, p.580. 
42. FLOWER, R.J. Drugs which inhibit prostaglandin biosynthesis. Pharmacel. Rev., Baltimore, v.26, n.1, p.33-67, 1974.

43. FLOWER, R.J. Prostaglandins an related compounds. In: VANE, J.R. , FERREIRA, S.H, eds. Anti-inflammatory drugs, Berlin: Springer-Verlag, 1979. p.374-422. [Handbook of Experimental Pharmacology, v.50, pt.1.]

44. FLOWER, R.J. , MONCADA, S., VANE, J. R. Substâncias antiinflamatórias e analgésicas-antipiréticas; drogas empregadas no tratamento da gota. In: GILMAN, A.G. GOODMAN, L.S. , RALL, T.W., MURAD, F, eds. As bases farmacologicas da terapêutica. Rio de Janeiro: Guanabara, 1987 . p. 443-469.

45. FORBES, J.A. , BEAVER, W.T. , JONES, K.F., KEHM, C.J. , SMITH, W.K., GONGLOEE, C.M. , ZELEZNOCK, J.R. , SMITH, J.W. Effect of caffeine on ibuprofen analgesia in postoperative oral surgery pain. Clin. Pharmacol. Ther, St. Louis, v.49, n.6., p.674-684, 1991 .

46. FREISE, J., MAGERSTEDT, D. How does liposome entrapment change the pharmacokinetics of drugs. General considerations and results with methotrexate and cisplatin. In: SCHMIDT , K.H., ed. Liposomes as drug carriers. Stuttgart: Georg Thieme Verlag, 1986. p.182-210. [Symposium on Liposomes as Drug Carriers, 1985].

47. GADERTON, D. , HADGRAFT, J.W., RISPIN, W.T. , THOMPSON, A.G. The break-up and dissolution of phenindione tablets. Pharm. Acta Helv, Bern, v.42, n.3, p.152-162, 1967.

48. GIBALDI, M. Biopharmaceutics and clinical pharmacokinetics. 4. ed. Philadelphia: Lea \& Febiger, 1991. p.40-60, 65-79.

49. GILlESPIE, W.R. , DisANTO, A.R. MONOVICH, R.E., ALBERT, K.S. Relative bioavailability of commercial available ibuprofen oral dosage forms in humans. $J$. Bharm. Sci., Washington, v.71, n.9, p.1034-1038, 1982 . 
50. GORDON, R. E. , ROSANSKE, T.W. , FORNNER, D.E. , ANDERSON, N.R. , BANKER, G.S. Granulation technology and tablet characterization. In: LIEBERMAN, H.A., LACHMAN, L., SCHWARTZ, J.B.. eds. Pharmaceutical dosage forms: tablets. 2.ed. New York: Marcel Dekker, 1990. v.2. p.333.

51. GRYGLEWSKI, R.J. Screening and assessment of the potency of anti-inflammatory drugs in vitro. In: VANE, J.R. , FERREIRA, S.H, eds. Anti-inflammatory drugs. Berlin: Springer-Verlag, 1979. p.15. [Handbook of Experimental Pharmacology, v.50, pt.2.]

52. HANDBOOK of nonprescription drugs. 8 ed. Washington: Americam Pharmaceutical Association, 1986. p.201-203.

53. HANNULA, A. MARVOLA, M. AHO, E. Release of ibuprofen from hard gelatin capsule formulations. Effect of sodium bicarbonate as a desintegrant. Acta Pharm. Fenn., Helsinki, v.98, p. 131-134, 1989a.

54. HANNULA, A. MARVOLA, M. JONS, M. Release of ibuprofen from hard gelatin capsule formulations. Effect of modern disintegrants. Acta Pharm. Fenn. Helsinki, v.98, p.189-196, $1989 \mathrm{~b}$.

55. HANNULA, A. , MARVOLA, M. , KOPRA, T. Release of ibuprofen from hard gelatin capsule formulations. Effect of various additives and filling method. Acta Pharm. Eenn., Helsinki, v.98, P.11-20, 1989c.

56. HELMAN, A. , DALESIO, G.N. Brediccion de la estabilidad de drogas $y$ medicamentos. Buenos Aires: CAEME, 1971. p.131132 .

57. HIGUCHI T. ELOWE N. L. , BUSSE W. L. The Physics of tablet compression $V$. Studies on aspirin, lactose, lactoseaspirin, and sulfadiazine tablets. J. Am. Pharm. Assoc. Sci Ed., Washington, v.43, n.11, p.685-689, 1954. 
58. HIGUCHI, $T$. KURAMOTO, $R$. Study of possible complex formation between macromolecules and certain pharmaceuticals. I. Polyvinylpyrrolidone with sulfathiazole, procaine hydrochloride, sodium salicylate, benzil penicillin, chloramphenicol, mandelic acid, caffeine, theophylline, and cortisone. J.Am. Pharm. Assoc. Sci. Ed., Washington, v.43, n.7, p.393-397, 1954a.

59. HIGUCHI, $T$. KURAMOTO, $R$. Study of possible complex formation between macromolecules and certain pharmaceuticals. II. Polyvinylpyrrolidone with pamonobenzoic acid, aminopyrine, benzoic acid, salicylic acid, p-hycloxybenzoic acid, m-hydroxybenzoic acid, citric acid, and phenobarbital. J. Am. Pharm. Assoc. Sci. Ed. Washington, v.43, n.7, p.398-401, $1954 \mathrm{~b}$.

60. HIGUCHI, W.I., LAU, P.K., HIGUCHI, T., SHELL, J.W. Polymorphism and drug availability. Solubility relationships in the methylprednisolone system. J. Pharm. Sci., Washington, v.52, n.2, p.150-153, 1963.

61. HIGUCHI T., RAO A. N., BUSSE W. L., SWINTOSKY V. J. The Physics of tablet. II. The influence of degree of compression on properties of tablets. $J$. Am. Pharm. Assoc. Sci Ed., Washington, v.42, n.4, p.194-200, 1953.

62. IMAI, T., KIMURA, S., IIJIMA, T., MIYOSHI, T. , UENO, M. , OTAGIRI, M. Rapidly absorbed solid oral formulations of ibuprofen using water-soluble gelatin. J. Pharm. Bharmacel., London, v.42, n.9, p.615-619, 1990.

63. INFORMACION de medicamentos. Madrid, Ministério de Sanidad y Consumo de Spana, 1989, v.2

64. INTERNACIONAL pharmacopoeia 3. ed. Genebra: World Health Organization, 1981. v.2, p.151-153.

65. ITIOLA, O.A. , PIPEL, N. Studies on metronidazole tablet formulations. $J$ Pharm. Pharmacel., London, v.38, n.2, p.81-86, 1986 . 
66. JACOB, J.T., PLEIN E.M. Factors affecting dissolution rate of medicaments from tablets II. Effect of binder concentration, tablet hardness, and storage conditions on the dissolution rate of phenobarbital from tablets. $J$. Bharm. Sci., Washington, v.57, n.5, p.802-805, 1968.

67. JASINI, M.K. , DOWNIE, W.W. , SAMUELS, B.M. , BUCHANAN, W.W. Ibuprofen in rheumatoid arthritis. Clinical study of analgesic and anti-inflammatory activity. Ann. Rheum. Dis., London, v.27, p.457-462, 1968.

68. KARARLI, T.T. NEEDHAM, T.E., SEUL, C.J. , EINNEGAN, P.M. Solid-state interaction of magnesium oxide and ibuprofen to form a salt. Bharm. Res,. Stuttgart, v.6, n.9, p.804-808, 1989.

69. KEMPTHORNE, 0 . The design and analysis of experiments. New York: John Wiley, 1952. p.390-409.

70. KHAN, K. A. , RHODES, C. T. An evaluation of five commercially available tablet desintegrants for possible use in insoluble direct compression systens. $J$. Pharm. Bharmacel., London, v.23, suppl, p.261s-262s, 1971.

71. KIMURA, S., IMAI, T. OTAGIRI, M. Effect of low-molecular casein and gelatin on absorption of ibuprofen after oral and rectal administration. Pharm. Acta Helv., Bern, v.66, n. 4, P.120-124, 1991 .

72. LANZA, F.L. Endoscopic studies of gastric and duodenal injury after the use of ibuprofen, aspirin and other nonsteroidal antiinflammatory drugs. Am. J.Med. New York, v.77, n.1A, p. 19-24, 1984 .

73. LEVY, G. ANTKOWIAK, J.M. , PROCKNAL, J.A. , WRITE, D.C. Effect of certain tablet formulation factors on dissolution rate of the active ingredient II. Granule size, starch concentration, and compression pressure. $J$ Pharm. Sci., Washington, v.52, n.11, p.1047-1051, 1963.

74. LEVY, G. , GUMTOW, R.H. Effect of certain tablet formulation factors on dissolution rate of the active ingredient III. Tablet lubricants. JPharm. Sci., Washinton, v.52, n.12, p.1139-1144, 1963 . 
75. LUZZI, L., PALMIERI, A. An overview of pharmaceutical applications. In: LIM, F., ed. Biomedical applications of microencapsulation. Boca Raton: CRC Press, 1984. p.1-17.

76. MARTINDALE the extra pharmacopoeia. 29. ed. London: Pharmaceutical Press, 1989. p.20-21.

77. MARVOLA, $M$. HANNULA, A-M, KLINGE, $\mathrm{E}$. KESKITALO, J . Effect of some cellulose derivatives as diluents on the bioavailability of ibuprofen capsules in man. Acta Pharm. Eenn. Helsinki, v.100, p.211-218, 1991.

78. MERCK index : an encyclopedia of chemicals, drugs and biologicals. 11. ed. Rahway, 1989. p.776.

79. MONCADA, S., FLOWER, R.J., VANE, J.R. Prostaglandinas, prostaciclina, tromboxano $\mathrm{A}_{2}$ e leucotrienos. In: GILMAN, A.G. , GOODMAN, L.S., RALL, T.W. , MURAD, F. eds. As bases farmacologicas da terapêtica. Rio de Janeiro: Guanabara, 1987. p. 433 .

80. MORRISON, J.C. , LING, F.W. , FORMAN, E.K. , BATES, G.W. BLAKE, P.G. ' VECCHIO, T.J', LINDEN, C.V. , O'CONNELL', M.J. Analgesic efficacy of ibuprofen for treatment of primary dysmenorrhea, South. Med. J, Birmingham, v.73, p. 999-1002, 1980 .

81. MURA, P. , LIGUORI, A. , BRAMANTI, G. , POGGI, L. Phase equilibria crystallinity and dissolution rates of ibuprofen-polyethylene glicol 20000 solid dispersions. Earmaco Ed. Prat, Pavia, v.42, n.6, p.157-164, 1987a.

82. MURA, P. , LIGUORI, A., BRAMANTI, G. Preparation and dissolution characteristics of solid dispersions of ibuprofen in various polyethylene glycols. Earmaco Ed. Prat., Pavia, v.42, n.6, p.149-156, 1987 b.

83. MURA, P. , LIGUORI, A. , BRAMANTI, G. Solid dispersions of ibuprofen in urea. Effects of urea on dissolution. Earmaco Ed. Prat., Pavia, v.41, n.12, p.377-387, 1986.

84. NESIC, M. , CVETKOVIC, N., POLIC, D. A contribution to the knowledge of the consolidation mechanism of ibuprofenpolyvinylpyrrolidone system. Acta Pharm. Jugosl., Zagreb, v. 40, p. $545-550,1990$. 
85. PALVA, E.S. , KONNO, K., VENHO, V.M.K. Bioavailability of ibuprofen from three preparations marketed in Finland. Acta Pharm. Fenn., Helsinki, v.94, p.31-35, 1985.

86. PARROT, E.L. Compression. In: LIEBERMAN, H.A. LACHMAN, L. , SCHWARTZ, J.B., eds. Pharmaceutical dosage forms: tablets. New York: Marcel Dekker, 1990. v.2, p.201-243.

87. PARROT, E. L. Bharmaceutical technology: fundamental pharmaceutics. Minneapolis: Burgess, 1970. p.124-130.

88. PERRY, S.J. , STREETE, P.J. , VOLANS G.N. Ibuprofen overdose: the first two years of over-the-counter sales. Hum. Toxicol., v.6, n.2, p.173-178. Apud: COMPREHENSIVE Medline (CD-Rom). Peabody, EBSCO, 1991.

89. PHARMACOPOEIA of Japan (english version) 11. ed. Tokyo: The Society of Japanese Pharmacopoeia, 1986. p.609-610.

90. PLAIZIER-VERCAMMEN, J.A. , De NEVE, R.E. Interaction of povidone with aromatic compounds II: Evaluation of ionic strength, buffer concentration, temperature, and $\mathrm{pH}$ by factorial analysis. J. Pharm. Sci, Washington, v.70, n.9, p.1252-1256, 1981 .

91. REMINGTON'S pharmaceutical sciences. 18.ed. Easton: Mack, 1990. p.1116.

92. REPERTORIO farmaceutico italiano (REFI). 6. ed. Milano: CEDOF, 1992. P.A212-A214.

93. ROMERO, A.J. , GRADY, L.T. , RHODES, C.L. Dissolution testing of ibuprofen tablets. Drug. Dev. Ind. Pharm., New York, v.11, p.1549-1586, 1988. Apud: Int. Pharm. Abstr., Bethesda, v.26, n.10, abstr. n. 2606263, 1989.

94. ROMERO, A. J. , LUKAS, G. , RHODES, C. T. Influence of different sources on the processing and biopharmaceutical properties of high-dose ibuprofen formulations. Pharm. Acta Helv, Bern, v.66, n.2, p.34-43, 1991. 
95. SHEFTER, E. , HIGUCHI, T. Dissolution behavior of crystalline solvated and nonsolvated forms of some pharmaceuticals. $\mathrm{I}$. Pharm. Sei, Washington, v.52, n.8, p.781-791, 1963.

96. SHEN, T.Y. Prostaglandin synthetase inhibitors I. In: VANE, J.R. , EERREIRA, S.H. Anti-inflammatory drugs, Berlin: Springer-Verlag, 1979. p.313-323. [Handbook of Experimental Pharmacology, v.50, pt.1]

97. SITTIG, M. Pharmaceutical manufacturing encyclopedia. 2 . ed. New Jersey: Noyes Data, 1988. p.796-798.

98. SLAVIC-SVIRCEV, V., HEIDRICH, G. , KAIKO, R.E. , RUSY, B.E. Ibuprofen in the treatment of postoperative pain. Am. J. Med. New York, v.77, n.1A, p.84-86, 1984.

99. SOLVANG, S., FINHOLT, P. Effect of tablet processing and formulation factors on dissolution rate of the active ingredient in human gastric juice. $J$. Pharm. Sci., Washington, v.59, n.1, p.49-52, 1970.

100. STAVCHANSKY, S.A., McGINITY, J.W. Bioavailability in tablet technology. In: LIEBERMAN, H.A., LACHMAN, L., SCHWARTZ, J. B., eds. Bharmaceutical dosage forms: tablets. 2. ed. New York: Marcel Dekker, 1990. v.2, p.392-569.

101. STEAD, J.A. B FREEMAN, M. , JOHN, E.G. WARD, G.T. bioavailability studies. Int. $J$. Pharm, Amsterdam, v.14, n.1, P.59- 72, 1983 .

102. UNITED States pharmacopeia 22 ed. Rockville: United States Pharmacopeial Convention, 1989. p.682-683, 1577-1579.

103. VANE, J.R., BOTTING, R. Inflammation and the mechanism of action of anti-inflammatory drugs. EASEB $J$, Bethesda ,v.1, n.2, p.89-96, 1987.

104. VANE, J.R. Inhibition of prostaglandin synthesis as a mechanism of action for aspirin-like drugs. Nature New Biel., London, v.231, p.232-235, 1971. 
105. WAGNER, J.G. Biopharmaceutics. 15. Desintegration of dosage forms in vitro and in vivo part $V$. Drug Intell. Clin. Pharm., Cincinnati, v.3, n.12, p.357-363, 1969.

106. WAGNER, J.G. , Eundamentals of clinical pharmacokinetics. Hamilton: Drug Intelligence Publications, 1975. p.10-19.

107. WARD, J. B., TRACHTENBERG, A . Evaluation of tablet disintegrants. Drug Cosmet. Ind, New York, v.62, n.1, p.35-36, 92, 110-111, 1962 .

108. WARD, J.R. Update on ibuprofen for rheumatoid arthritis. Am. J.Med., New York, v.77, n.1A, p.3-9, 1984. 109. WIESEND, B. Vergleichende untersuchung
handelsüblicher qur qualität
ibuprofen-práparate. Frankfurt, v.133, n.16, p.27-31, 1988. 
112

RESUMO 
o ibuprofeno é um anti-inflamatório não-esteroidal (AINE) que possui propiedades analgésicas e antitérmicas e é empregado na terapêtica em casos dores discretas e moderadas, artrite reumatóide, osteoartrite e dismenoréia primária, nas concentrações de 200, 300, 400 e $600 \mathrm{mg}$. Entretanto, a formulação contendo $200 \mathrm{mg}$ não està disponivel no mercado farmacêtico brasileiro.

No presente trabalho, foi desenvolvida uma formulação de comprimidos de ibuprofeno $200 \mathrm{mg}$ que apresentou, além de outras caracteristicas fisico-quimicas adequadas, um otimo perfil de dissolução.

Foram testadas oito formulaçǒes, obtidas a partir de um projeto fatorial fracionado, avaliando-se diversos excipientes.

Além disto, as formulações foram submetidas à temperatura ambiente, $37^{\circ} \mathrm{C}$ e $50^{\circ} \mathrm{C}$, e analizadas à 30 e 60 dias, com o objetivo de avaliar as transformações fisicas que podem ocorrer durante o armazenamento das mesmas.

Os resultados das anàlises fisico-quimicas foram tratados estatisticamente, utilizando-se o programa STATGRAECS, através de uma analise exploratoria e de um estudo de efeitos. Concluiu-se, então, que a melhor formulação foi a sequinte: IBUPROFENO - 200; AMIDO - 47; LACTOSE - 72; CELULOSE MICROCRISTALINA - 23; ESTEARATO DE MAGNESIO - 8. 
ABSTRACT 
Ibuprofen is a non steroidal antiinflamatory drug (NSAD), that has analgesic and antipyretic properties. It is used in terapeutic cases of mild to moderant pain, rheumatoid arthritis, osteoarthritis, and primary dysmenorrhea, in the 200 , 300,400 , and $600 \mathrm{mg}$ of concentration. In the Brazilian pharmaceutical market the formulation of $200 \mathrm{mg}$ doesn't exist.

In this study, a formulation of ibuprofen was developed for $200 \mathrm{mg}$ tablets, that has suitable physical-chemical properties and an exellent dissolution profile.

The eight formulations tested were obtained from factorial designs, evaluating several excipients. These formulations also had been submitted at room temperature, 37 ०C , and $50{ }^{\circ} \mathrm{C}$ and were analised at 30 and 60 days, with the objective to evaluate the physical transformatiom that could have occured during that time.

The results were tested statisticaly by the STATGRAFCS program, using the exploratory analysis and the efects study. The final results showed that the best formulation was: IBUPROFEN 200; STARCH - 47; LACTOSE - 72; MICROCRYSTALLINE CELLULOSE - 23; MAGNES IUM STEARATE - 8. 